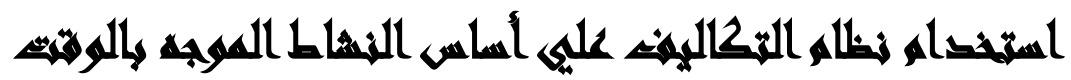

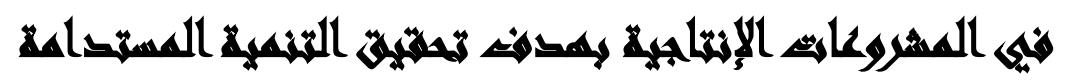

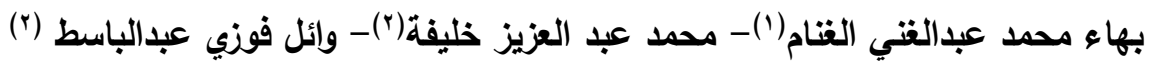
() طالب دراسات عليا، معهد الدراسات والبحوث البيئية، جامعة عين شمس ؟ ؟) كلية التجارة، جامعة عين شمس درس

\begin{abstract}
list

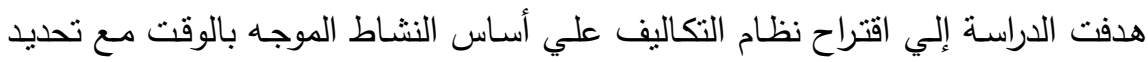

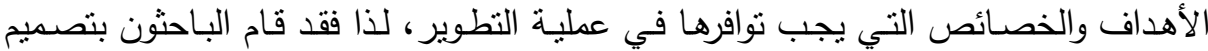

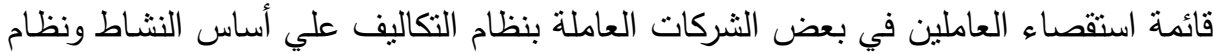

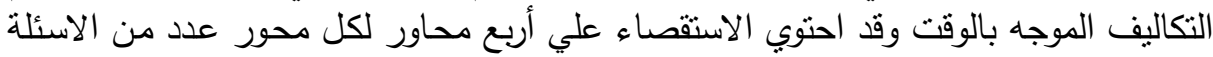

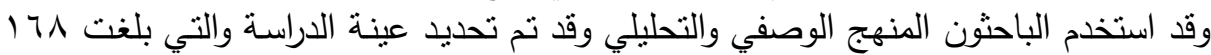
وقد توصل البـاحثون إلي: وجود علاقـة ايجابيـة بين تطبيق نظـام التكلفة علي أسـاس

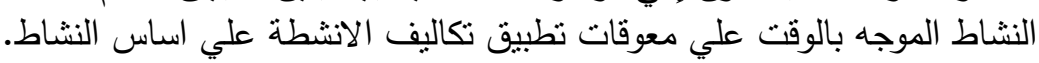

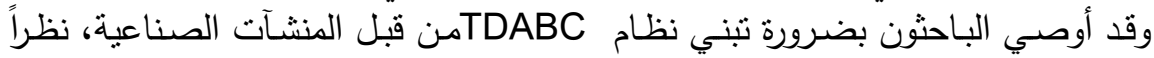

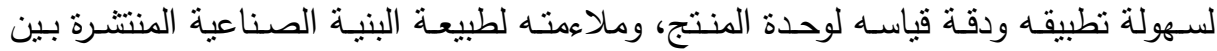

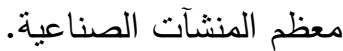

\title{
anadl
}

فى ظل عالم معاصر يتسم نظامه الاقتصادى بالتطور السريع فى شتى مجالاته

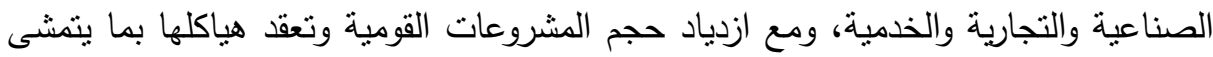
مع التطور التكنولوجى فى وسائل الانتاج، برزت محاسبة التكاليف كعلم مستقل له أهيدية

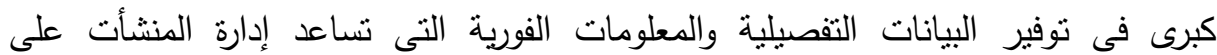

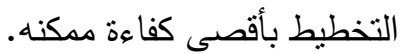

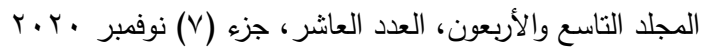

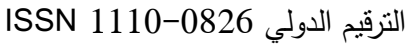


الأمر الذى جعل المنشأت مضطره إلى الاعتماد على أنظمة تكاليف منطورقتلائم بيئة الأعمال الحديثة، وتوفر لها الكثير من البيانات الازمه لإتخاذ القرارات الرشيده خاصة فيما يتعلق بالسياسات الإنتاجية، وتسعير المنتجات، وتحديد الحجم الأمتل للمزج السلعى من أجل الإنل

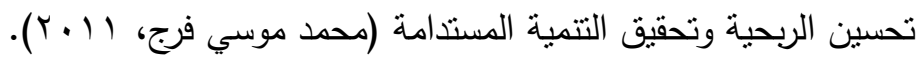
وبناءً عليه كان من الضرورى ظهور نظام جديد لمحاسبة التكاليف يلبى احتياجات الإدارة فى الحصول على المعلومات بالكم والنوعية والدقة والسرعة المطلوبة ويعزز قدرتها على الرقابة وتقييم الأداء واتخاذ القرارات، الأمر الذى تطلب تطبيق نظام التكاليف على أساس

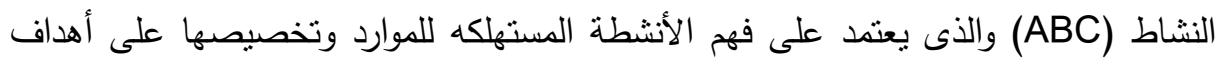

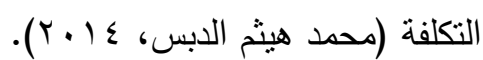
وعلى الرغم من تعدد منافع تطبيق نظام (ABC) فقد تعرض لانتقادات عديدة أهمها: • كونه مدخلا يستخدم فى الأجل الطويل بشكل أكثر ملائمة من الأجل القصير.

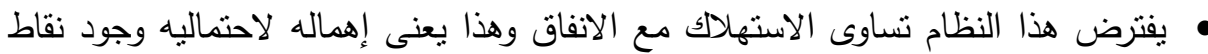

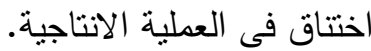
• كما يعاب عليه عدم المرونة حيث تضطر المنشاة إلى تحمل تكاليف وجهود تطبيقة مرة أخرى إذا قررت إعادة هيكله أحد أقسامها الانتاجية. ونظراً للانتقادات الموجهه إلى نظام (ABC) تطلب الأمر التفكير فى نظام اخر يستقيد من إيجابيات نظام (ABC) ويتلافى سلبياته، لذلك اتجه " كابلان " و " اندرسون" إلى تطويره بنظام التكاليف على أساس النشاط الموجه بالوقت (Activity Based costing ويعتبر النظام أسلوبا جديدا فى تخصيص التكاليف يفترض أن الوقت (TD-ABC) ( Time المستتفذ فى نتفيذ أى نشاط يعد المقياس الوحيد لطاقة الموارد المستهكة فى نتفيذ ذلك النشاط

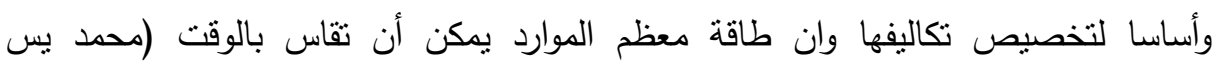

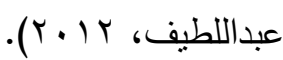

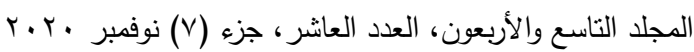

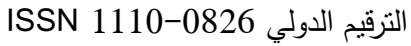


ويعرف نظام ( TD-ABC) بأنه نظام يعتمد على تقدير عاملين (مقياسين) هما:

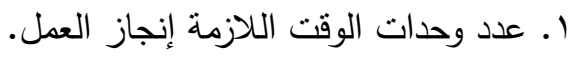
r . تكلفة الوحدة من الوقت.

ثم يحسب تكلفة المنتج اعتماداً على هذين العاملين.

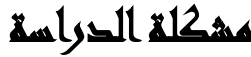

بالرجوع إلي دراسة كل من : (محمد الخطيب نمر وآخرون، rا.ب) و (محمد علي

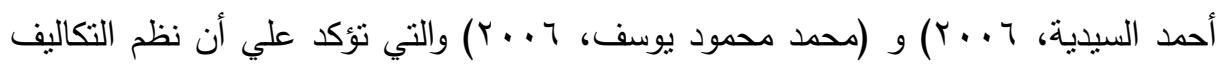
من ألأدوات الهامة التي تستخدمها الإدارة في عملية التخطيط والرقابة، وتعمل علي مساعدة الإدارة في تحقيق كفاءة العمليات وذللك من خلال أحكام الراقبة علي مجموعة العوامل التي

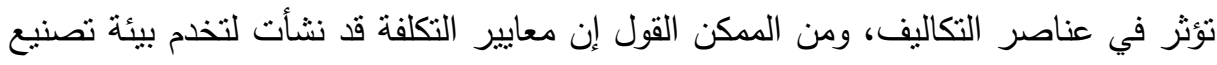

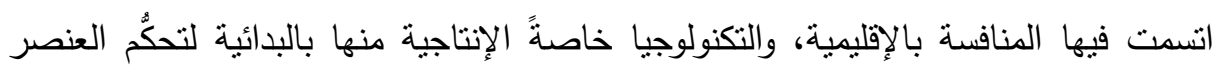
البشري في تشغيلها، كما اتسمت هذه البيئة بالاحتفاظ بالمخزون بأحجام كبيرة، وبإنتاج منتجات نمطية ذات دورة حياة طويلة وتباع بأسعار مستقرة نسبياً لحجم كبير ومستقر أيضاً من العملاء. وبناءً على ما سبق يناقش الباحثون كيفية نطوير نظم التكاليف حتى تستعيد دورها الرقابي في ظل بيئة التتغيل الحديثة، ويقترح البحث الحالي منهجاً للتطوير من خلاد استخدام

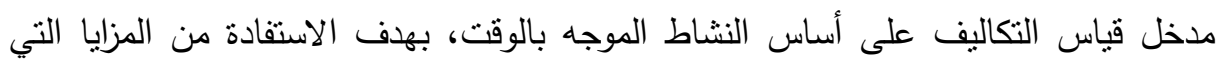

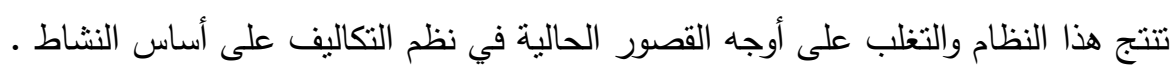
وسيساعد ذلك في صياغة إطار مفاهيمي لعملية نطوير نظم التكاليف في ظل بيئة

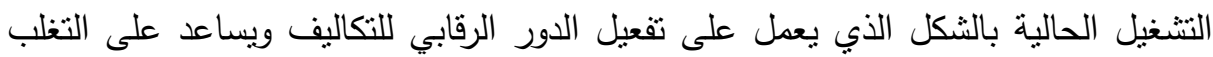
على أوجه القصور الحالية عند تطبيقها عملياً.

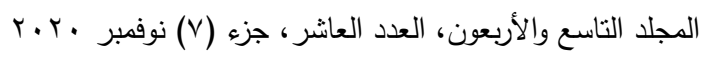

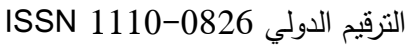


أسرئلا المهيه

1-ما الأهداف والخصائص التي يجب نوافرها في التطوير المرجو في نظم التكاليف لدقابلة التغيرات في بيئة التصنيع الحديثة؟ التهدي

r-ما الإطار الفكري الذي يحكم عملية تطبيق مدخل قياس التكاليف على أساس النشاط الموجه بالوقت، وما هي النتائج المتحققة من وراء هذا التطبيق؟ ب-ما الكيفية الني من المككن تطبيق هذا النظام في المشروعات القومية؟ ع-ما المستويات المختلفة الخاصة بنطبيق التكاليف على أساس النشاط الموجه بالوقت ؟ ه-ما خطوات هذا التطبيق في الواقع العملي؟

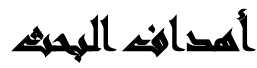

$$
\text { يهدف البحث إلى: }
$$

ا ـ اقتراح دراسة بحثية للتعامل مع المشكلة المشار اليها من خلال نظام التكاليف على أساس النشاط الموجه بالوقت مع تحديد الأهداف والخصائص التي يجب نوافرها في عملية •

r. دراسة نظام التكاليف على أساس النشاط الموجه بالوقت بكافه جوانبه من حيث المفهوم

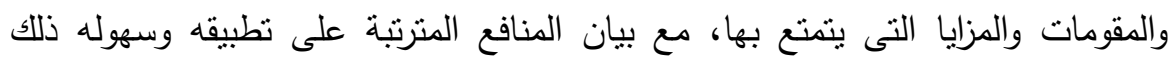

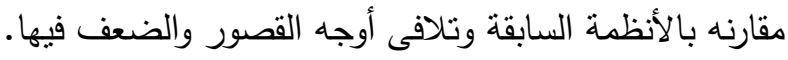
r. إبراز دور نظام التكاليف على أساس النشاط الموجه بالوقت وتأثيه الثيره فى إتخاذ القرارات الإدارية فى المشروعات القومية.

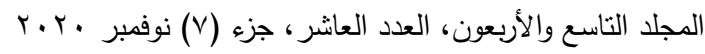

$$
\begin{aligned}
& \text { التزقيم الدولي 0826-0 التون، }
\end{aligned}
$$




$$
\begin{aligned}
& \text { مجلة العلوم البيئية } \\
& \text { معهد الدراسات والبحوث البيئية - جامعة عين شمس لئ } \\
& \text { بهاء محمد عبدالغني الغنام وآخرون }
\end{aligned}
$$

\section{أهمية الهيمثي}

ترجع أهمية هذا البحث إلى الاتي: تكمن أهمية الدراسة في أنها تهتم بنظام التكاليف علي

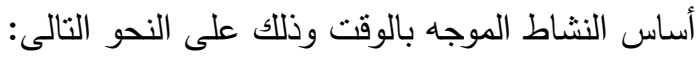

أ- الأهمية العملية تتبع أهمية الدراسة العلمية في : العاطئ

1-أنها تتعلق بعمليات التخطيط والرقابة واتخاذ القرارات في الواقع العملي، وبالتالي فإنه التهان تطوير هذا الأسلوب يتوافق مع بيئة النتغيل الحديثة وذلك من خلال استخدام نظام

$$
\text { التكاليف على أساس النشاط الموجه بالوقت. }
$$

r-محاولة التعامل مع النقص في الابحاث وخاصة التطبيقي ومنها فيما يتعلق بنطوير نظم

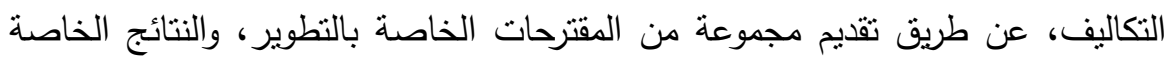

$$
\text { بالتطبيق لهذه المقترحات. }
$$

ب- - الأهمية العلمية تتبع أهمية الدراسة العلمي في: لجأ الباحثون إلى الإهتمام باستخدام

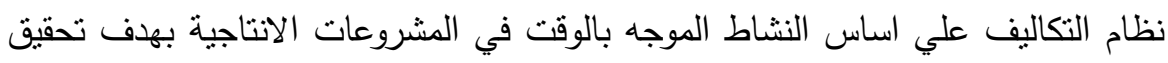
التتمية المسدامة للثركات الاستثمارية التي تعمل بهذا النظام.

\section{هزور اللهنش}

$$
\text { يقوم البحث على الفرضين التاليين: }
$$

1-لا يوجد تأثير معنوي ذو دلالة إحصائية لنظام التكلفة علي اساس النشاط الموجه بالوقت

$$
\text { على معوقات تطبيق تكاليف الانشطة علي اساس النشاط. }
$$

ץ- لا يوجد تأثثير معنوي ذو دلالة إحصائية لنظام التكلفة علي اساس النشاط الموجه بالوقت

$$
\text { على إتخاذ القرارات . }
$$

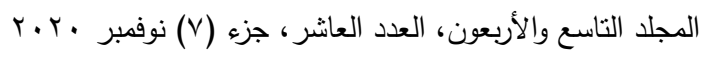

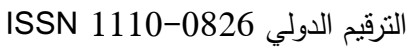




\section{مشور المهند}

يتتاول الباحثون هذا البحث من زاوية:

1-دراسة نظام التكاليف على أساس النثاط الموجه بالوقت ومقارنته بنظام التكاليف على لبـ أساس النشاط، لذلك يخرج عن نطاق البحث باقى أنظمة التكاليف الأخرى منل نظرية

$$
\text { القيود واستهلاك الموارد ألخ بناسن }
$$

r-بنت نطبيق نظام التكاليف على أساس النشاط الموجه بالوقت على المشروعات القومية، لذلك يخرج عن نطاق البحث باقى الأنشطة سواء صناعية أو خدمية أو تجارية.

\section{AهAll}

$$
\text { اعتمدت منهجية البحث على أسلوبين هما: }
$$

الأسلوب النظرى: الذى يعتمد على دراسة وتحليل الكتابات السابقة فى هذا المجال سواء من الناحية النظرية أو النطبيقية المتعلقة بموضوع البحث بهدف تكوين الإطار النظرى.

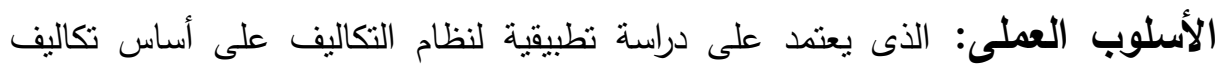
النشاط الموجه بالوقت بإنباع منهج دراسة الحالة على إحدى المشروعات القومية داخل جمهورية مصر العربية، وتحليل الآثار الناتجة عن هذا التطبيق للوصول إلى نتائج البحث وتوصياته.

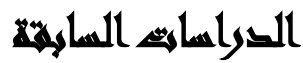

\section{- 1}

أساس النشاط لإدارة التكلقة اللوجستية فى ضوء مستجدات الأزمة المالية العالمية

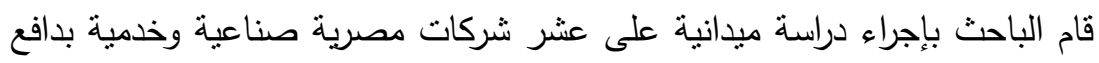
التعرف على أهمية الأنشطة اللوجستية الموجودة ضمن هذه الوحدات الإقتصادية، وكيفية

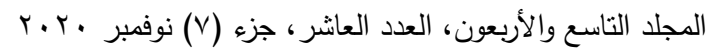

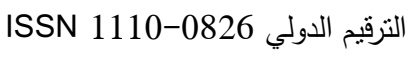




$$
\begin{aligned}
& \text { مجلة العلوم البيئية } \\
& \text { معهد الدراسات والبحوث البيئة - جامعة عين شمس لئية } \\
& \text { بهاء محمد عبدالغني الغنام وآخرون }
\end{aligned}
$$

تحديد التكاليف الخاصة بها، ومعرفة الطرق المستخدمه فى قياسها، وتوضيح دور منهج تكاليف النشاط الموجه بالوقت فى قياس تكلفة الأنشطة اللوجسنية غير المباشرة من أجل تخفيض تكلفة المنتج.

وتوصلت الدراسة إلى وجود تأثير مباشر وغير مباشر حول إمكانية استخدام نظام تكاليف النشاط الموجه بالوقت فى قياس تكلفة الأنشطة اللوجستية بهدف السيطرة عليها في ضوء الأزمه المالية العالمية.

: بعنوان : Tse M. S. C. \& Gong M. Z., 2009 : براسة "Recognition of Idle Resources in Time-Driven Activity-Based Costing and Resource Consumption Accounting Models

تتاولت هذه الدراسة كل من أنظمة (ABC) و (TDABC) ومحاسبة استهلاك الموارد

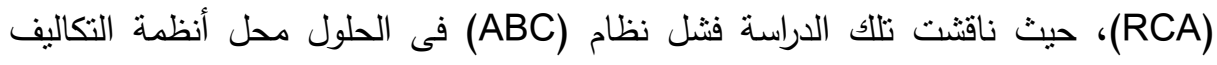

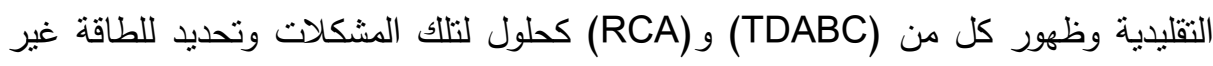

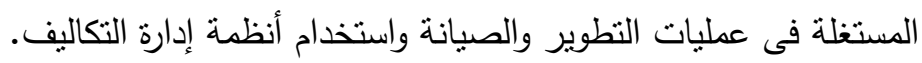
وتوصلت هذه الدراسة إلى النتائج التالية: 1- يعرض نظاما (RCA) و (TDABC) فلسفتين مختلفتين فى مجال تطوير أنظمة إدارة

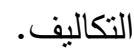

r- تم تصميم نظام (TDABC) ليبسط تطبيق أنظمة إدارة التكاليف من خلال إعتماد قياس واحد لقدرة الموارد.

r- دراسة : Lelkes 2009 : بعنوان :"SIMPLIFYING ACTIVITY-BASED COSTING"

تتاولت هذه الدراسة استعراض الأنظمة المنطوره واللاحقة لنظام (ABC) كالأنظمة

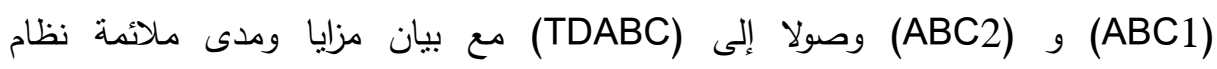

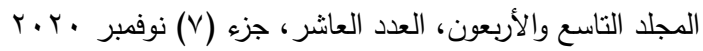

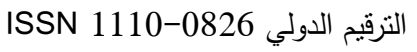


(TDABC) والمنشأت محل الدراسة . ماتصات وتوصلت الدراسة إلى النتائج النالية: ولن ا- إن تبنى نظام (ABC) يمكن أن يعرقل وجود نظام تكنولوجيا معلومات قوى .(STRONG IT)

r- تمتتع معظم الثركات عن استخدام نظام (ABC) لأنها تشعر أن الفوائد المرجوه منه لا تفوق تكاليف تطبيقة، كما أن هذا النظام لا يعزز الرقابة على التكاليف.

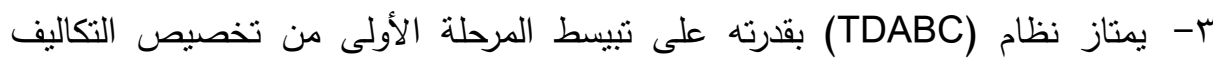
مقارنة بنظام (ABC) إلا أنه يبقى على التعقيد ذاته فى المرحلة الثانية من التخصيص. ؛ - دراسة Oker \& Adıgüzel , 2010 : بعنوان

"Time-Driven Activity-Based Costing:

An Implementation in a Manufacturing Company"

هدفت هذه الدراسة إلى إظهار فعالية وتفوق نظام (TDABC) على الأنظمة التقليدية فى توفير معلومات أكثر ملائمة ودقة حول ربحية المنتج ومستوى الاستفادة من الطاقة المتاحة للمنشأة، ومدى إمكانية تطبيقها فى القطاع الصناعى. وتتاولت هذه الدراسة نطبيق (TDABC) فى شركة صناعية نركية تدعى (AYSAN)

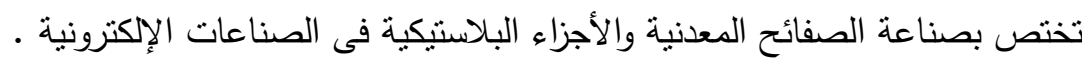
وتوصلت الدراسة إلى النتائج النالية: 1- اسنطاع نظام (TDABC) كنظام تكاليف حديث فى القضاء على الصعوبات التى واجهت نظام (ABC) من خلال التطوير بما يتلاعم مع تغير الأنشطة. r- يمكن تحديث (TDABC) ببساطة حتى بعد تطبيقه فى حالة قيام المنشأة بإعادة هيكلة خطوط الإنتاج من خلال استخدام المعدلات الوقتية على عكس (ABC).

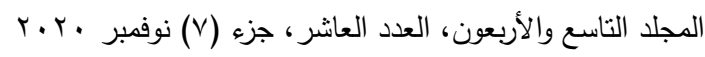

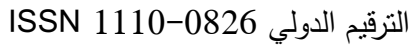




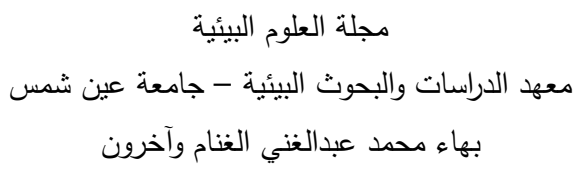

ه : بعنواسة : Stout \& Propri, 2011

:'Implementing Time-Driven Activity-Based Costing at a Medium-Sized Electronics Company"

قامت هذه الدراسة بإجراء مقارنة بين نظامى التكاليف (ABC) و (TDABC) من خلال

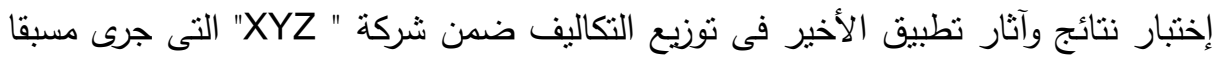

تطبيق نظام (ABC) عليها بنجاح عام V. . r. وترتب عليه نتائج مرضية جدا على صعيد

دقة قياس التكاليف وتوزيعها.

وهدفت هذه الدراسة إلى إظهار المقدرة الكامنة لنظام (TDABC) ودوره الهام فى إعتماد

أنظمة تخطيط موارد المشروع بالترابط مع أنظمة محاسبة التكاليف الحديثة. وتوصلت الدراسة إلى النتائج التالية:

1- يوفر نظام (TDABC) بيانات أكثر دقة عن التكاليف عما يقدمة (ABC) لكنها ليست

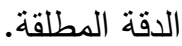

r- تعديل نظام (TDABC) أسهل مما هى عليه فى نظام (ABC).

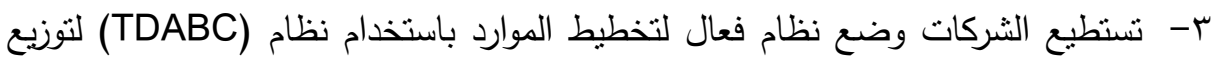

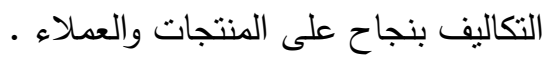

צ- دراسة محمد يس عبد اللطيف r 1 بr: بعنوان : تحليل ربحية العميل باستخدام منهج التكلفة على أساس النشاط الموجه بالوقت - دراسة حالة على أحدى الفنادق الكبرى بالمملكة

يهدف البحث إلى تحديد مدى إمكانية إجراء تحليل ربحية العميل إستتادا إلى نظام التكلفه على أساس النشاط الموجه بالوقت بتطبيقه على أحد الفنادق الكبرى فى المملكة العربية السعودية وذلك بهدف إتخاذ قرارات إدارية سليمة.

قامت الدراسة بإجراء مقارنة بين نظام التكلفه على أساس النشاط وبين نظام التكلفه على رلى أساس النشاط الموجه بالوقت، وتوصلت إلى النتائج النالية:

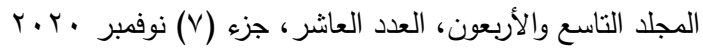

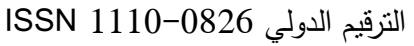


1- يمكن لنظام نظام التكلفه على أساس النشاط الموجه بالوقت (TDABC) استخدام

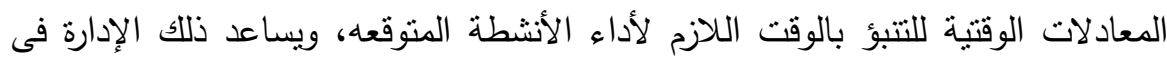
تحديد الأنشطة التى تستهلك وقت أكثر من اللازم ومن ثم مساعدة الإدارة فى إتخاذ قرارات

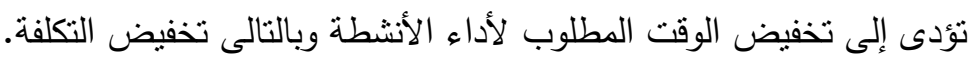

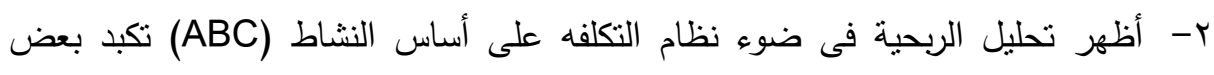

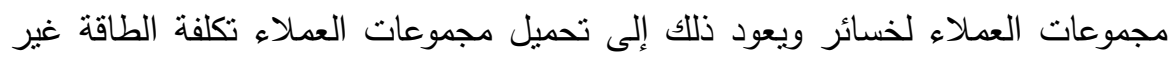
المستغله والتى تتتج عن قصور الإدارة فى الكثف عن الطاقة غير المستغله، فى حين حققت أرباحا فى ظل نظام التكلفه على أساس النشاط الموجه بالوقت (TDABC) نتيجة تحميلهم فقط بتكلفة الطاقة المستغلة.

V- دراسة محمد أحمد شاهين 17 ـ ب : بعنوان : إطار محاسبي مقترح لقياس وتحليل انحرافات التكاليف المعيارية على اساس النشاط الموجه بالوقت

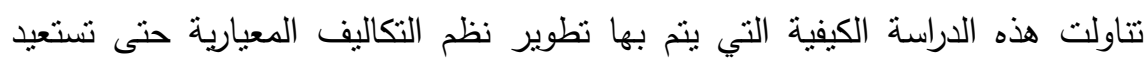
دورها الرقابي في ظل بيئة التتغيل الحديثة، وتتاولت مجموعة من الابحاث العديد من البدائل لطئل

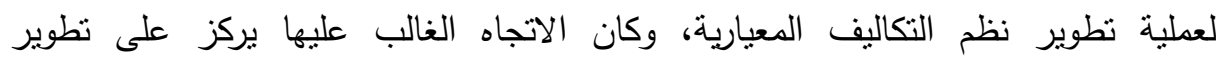

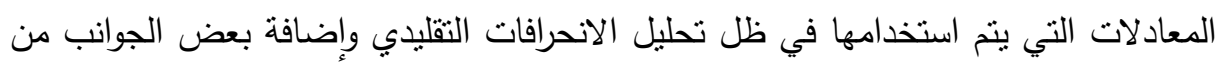
النشاط التي لم تكن تخضع لعملية المعايرة. وتوصلت هذه الدراسة إلى:

1-نظم التكاليف التقليدية فقدت كثيراً من مصداقيتها ومساهمتها في اضافة القيمة على القرارات التي تتخذها الادارة. r-نظم التكاليف المعيارية تعرضت للعديد من الانتقادات بشكلها التقليدي في ظل الظروف

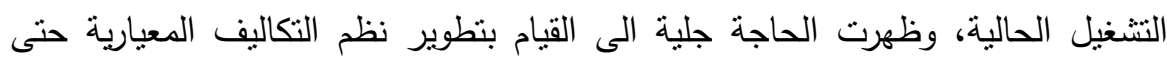
تتواكب مع الاحتباجات الخاصة بالإدارة في ظل بيئة التشغيل الحالية.

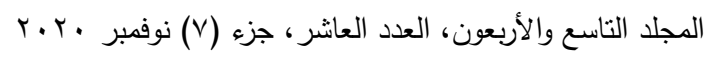

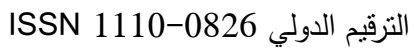


التعليق على الدراسات السابقة وتحديد الفجوة البحثية: بناءً على الدراسات السابقة تبين للباحث أن التعامل مع نظم التكاليف التقليدية في ظل بيئة الاعمال الحالية تعتبر بمثابة مشكلة فعلية استعصت على الحل، فلابد من إيجاد البديل المناسب لنظم التكاليف التقليدية، والتي تم تطويرها عن طريق استحداث العديد من الأساليب التي نركز على جانب النشاط لئل

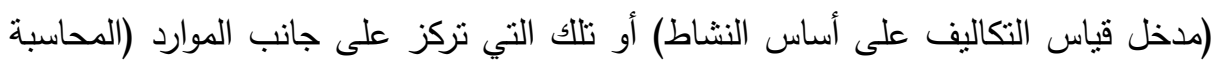
عن الموارد المستهكة، ومدخل قياس التكاليف على أساس النشاط الموجه بالوقت)، وكان تران تطويرها لزيادة الفعالية وملائمنها مع بيئة الاعمال الحديثة.

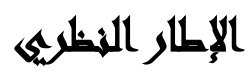

أصبحت محاسبة التكاليف أمرا ضروريا وحيويا لاستقرار المؤسسات الاقتصادية وقد رتها على المنافسة، وتهنم هذه المحاسبة بقياس التكلفة بما يخدم أغراضا معينة تساعد مسيري المؤسسة في أداء مختلف الوظائف التسيرية بأكبر قدر ممكن من الكفاءة

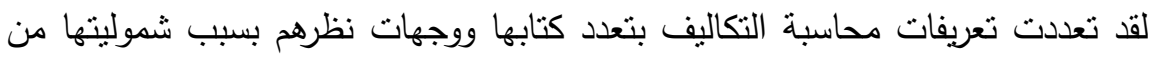

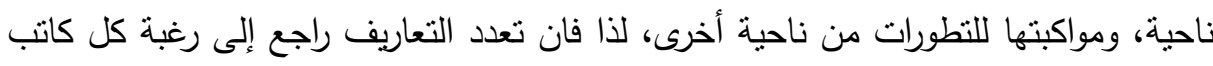

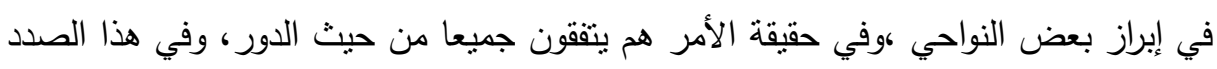

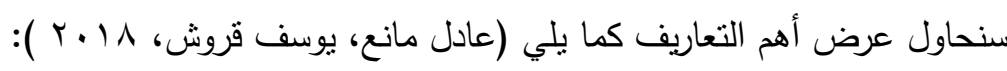

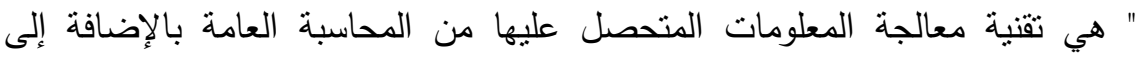
مصادر أخرى ،وتحليلها من اجل الوصول إلى نتائج يتخذ على ضوئها مسيرو المؤسسة

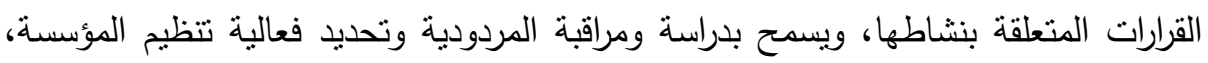

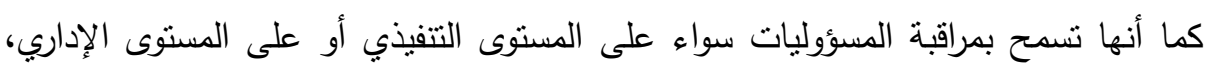
وتعتبر محاسبة التكاليف أداة ضرورية لتسبير المؤسسات "

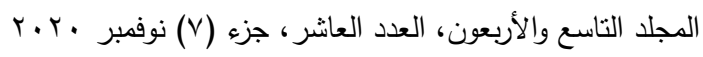

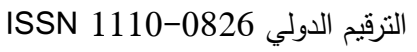


تطور محاسبة التكاليف: من المعلوم أن محاسبة التكاليف قد نثأت منأخرة عن المحاسبة المالية بما يقارب قرنين من الزمن، غير انه يمكن القول أن نشأة محاسبة التكاليف قدابه

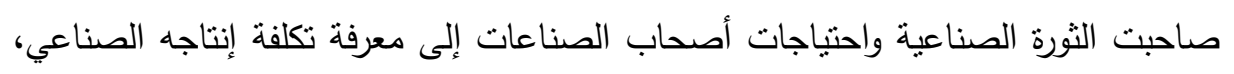
فقد تسأل أحد أثهر الكتاب في ميدان التكاليف في انجلترا سنة 1991 إعبد (عبد الحي مرعى،

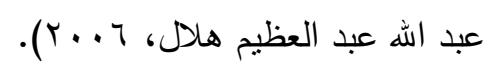
- أهداف محاسبة التكاليف: تهدف محاسبة التكاليف بحسابها للتكاليف وسعر التكلفة إلي

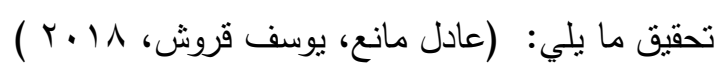
• ت تحديد قيمة المخزون باستعمال الجرد الدائم، وبهذا تسهل أيضا في عملية تحديد النتائج • • • •

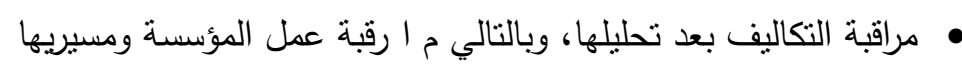

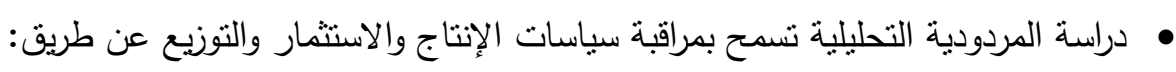
- - تسجيل التكاليف حسب اتجاهاتها (حسب الوظائف أو المنتجات)

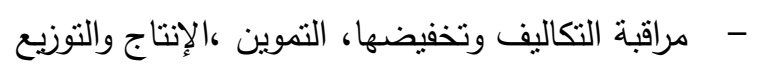
- - تسمح بقياس النتائج التحليلية - - تساهم في وضع الميزانيات التقديرية مفهوم نظام ال ABC : يعنبر نظام ال ABC من أهم الأنظمة التي لاقت استخداما واسع

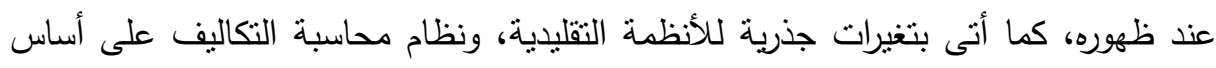

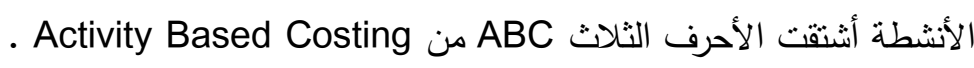

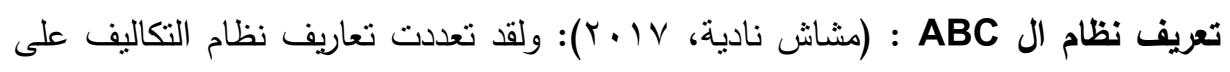
أساس الأنشطة ABC حسب اختلاف عدد من وجهات النظر ، فيعرفه بعض الأكاديميون أنه" عبارة عن نظام وليس أسلوب أو وسيلة وذلك لثموله على مكونات النظام من مدخلات ومعالجة المخرجات والتغذية العكسية.

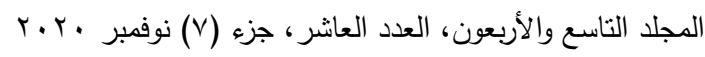

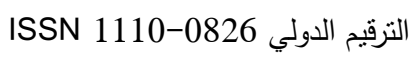


• يعرف نظام التكاليف على أساس الأنشطة ABC بأنه " مدخل تكلفة يركز على الأنشطة، حيث يستخدم تكلفتها كأساس لتحديد تكلفة أغراض تكلفة أخرى كأغراض تكلفة رئيسية

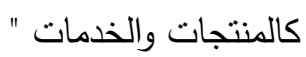
• هو طريقة تعود إلى تحسين الأنظمة التقليدية للتكاليف عن طريق التركيز على الأنشطة

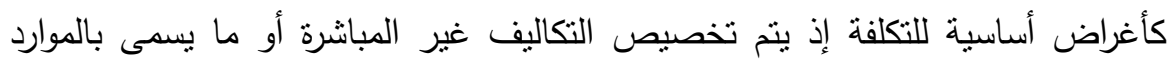

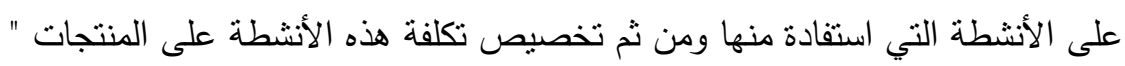
• كما عرف نظام التكاليف على أساس الأنشطة بأنه" يقيس تكلفة وأداء الأنشطة والموارد

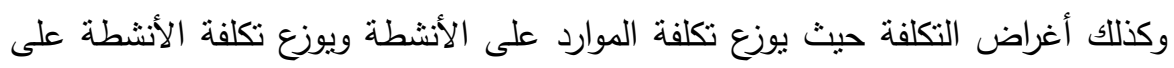
أغراض التكلفة بالاعتماد على استخداماتها وبسبب العلاقة السببية لمسببات التكلفة بالأنشطة " أي أنه يقوم على فكرة أن نوفير المنتجات أو الخدمات يحتاج إلى مؤسسات وأن هذه المؤسسات ثقوم على ممارسة عدة أنشطة لتحقيق غاياتها وأن تلك الأنشطة تحتاج إلى موارد وأن هذه الموارد بطبيعتها اقتصادية ولها تكلفة. وعليه ومن خلال التعاريف السابقة يمكن القول أن نظام التكاليف على أساس الأنشطة هو النها

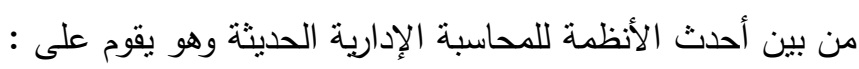
• تقييم قدرة المؤسسة على أداء الأنشطة من خلال تحديد وقياس مواردها.

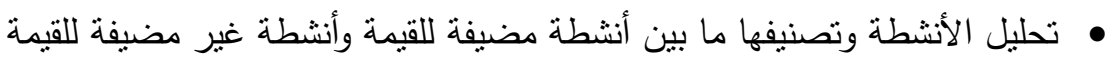
ه تحديد تكلفة مختلف الأنشطة وكذلك تكلفة الطاقة غير المستغلة.

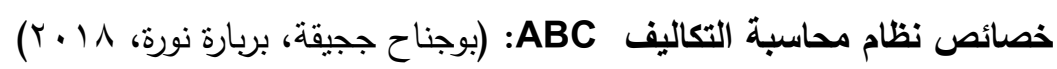
من أهم خصائص محاسبة التكاليف ما يلي: مدانية

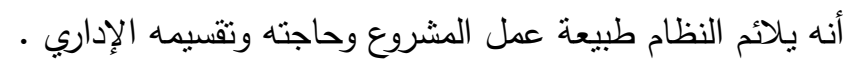

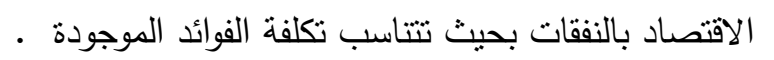
• أنه بتميز بالسهولة والوضوح حتى بمكن فهمه وتتفيذه في كل المستويات الإدارية والتتفيذية.

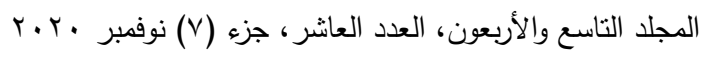

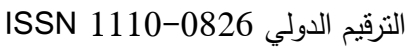


مجلة العلوم البيئية

معهد الدراسات والبحوث البيئية - جامعة عين شمس له

بهاء محمد عبدالغني الغنام وآخرون

• أنه يشتمل على وسائل الأحكام والرقابة على عناصر التكاليف .

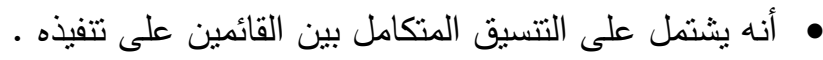

• أنه يشتمل على المقومات التي تمكن من إعداد التقدي ا رت اللازمة والمعايير المستخدمة لنداه

لدراسة المشاريع.

\section{إجزاعاهي السراسها}

أولاً: منهج الدراسة: نم استخدام الأسلوب النظري: (الأسلوب الوصفي التحليلي) لوصف الظاهرة موضوع الدراسة وتحليل بياناتها وبيان العلاقة بين مكوناتها، ويتسم هذا المنهج بأنه يقرب نتائج الدراسة من الواقع ويمكنها من وصف الظواهر بشكل دقيق. وكذلك تم استخدام الأسلوب الميداني: وأعتمد الباحثّن علي استخدام استمارات أستقصاء

\section{في تجميع البيانات الازمة.}

ثانياً: أدوات وعينة الدراسة: تم تحديد مجتمع البحث من بعض الثركات التي تطبق نظام التكاليف علي أساس النشاط وهي شركة المروة للاستيراد والتصدير، شركة المدكور للمشروعات، الثركة الهندية لخدمات المياه، شركة صقور مصر للتتمية العامة، شركة يونيتد

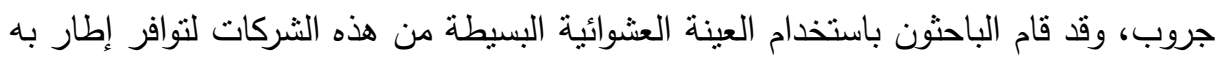

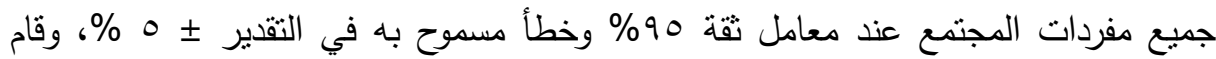
الباحث باستخدام معادلة إختيار العينة، وكان حجم العينة 171 مفردة وتم توزيعها على في مكردي

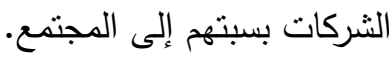
ثالثاً: تم تصميم استبيان اشتمل علي عدد اريعة محاور كالتالي:

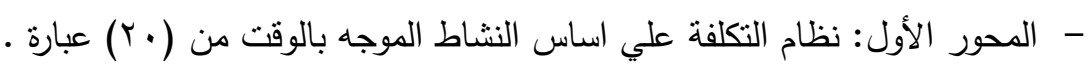
- المحور الثاني: معوقات نطبيق تكاليف الانشطة علي اساس النشاط من (• (1) عبارات . - المحور الثالث: إتخاذ القرارات من (^) عبارات . - المحور الرابع: الرضا عن تطبيق نظام التكلفة على اساس النشاط من (10) عبارة.

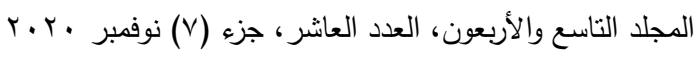

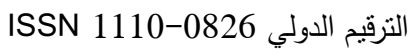




$$
\begin{aligned}
& \text { مجلة العلوم البيئية } \\
& \text { معهد الدراسات والبحوث البيئية - جامعة عين شمس لئ } \\
& \text { بهاء محمد عبدالغني الغنام وآخرون }
\end{aligned}
$$

صدق الأداة: للتحقق من صدق الأداة اعتمد الباحث صدق المحتوى إذ قام بعرض الأداة

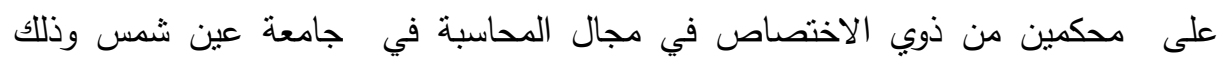
بغرض معرفة ما تقيسه الفقرات من الأداء المطلوب، ومدى صلة فئل فقرات المقياس بالمتغير

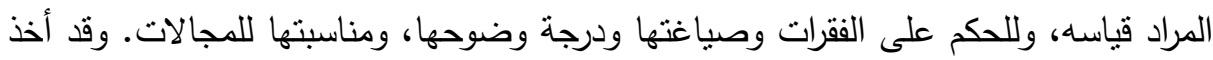

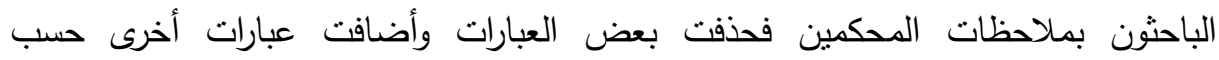

\begin{tabular}{|c|c|c|c|c|}
\hline الثبات & الصدامل & العبارات & المقياس & b \\
\hline., 900 & $\cdot, 91 \mathrm{Y}$ & r. & نظام التكلفة على اساس النشاط الموجه بالوقت & 1 \\
\hline$\cdot, 9 \leq \varepsilon$ & $\cdot, \wedge 94$ & 1. & النشاط ات ت تطبيق تكاليف الانشطة على أساس & $r$ \\
\hline$\cdot, \wedge 9 \mu$ & $\cdot, \vee \vee 9 \wedge$ & $\Lambda$ & إتخاذ القرارات & $r$ \\
\hline$\cdot, 9 \mu$ & $\cdot$, ค А т & 10 & الرضا عن تطبيق نظام التكلفة على اساس النشاط & $\varepsilon$ \\
\hline
\end{tabular}
توجيهاتهم - ت ن جدول ( 1 ) ): معاملات الصدق والثبات

من الجدول السابق يتضح أن معاملات الصدق والنبات مقبولة لأسئلة الاستبيان ككل ، لان جميع قيم معاملى الصدق والثبات تجاوزت (0, • ) في عينة الدراسة، وبالتالي يمكن القول

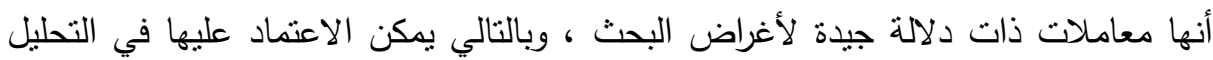
مع عدم استبعاد اي عنصر من عناصر المتغيرات محل الدراسة . الاساليب الإحصائية المستخدمة:

اعتمد الباحثون في تحليل البيانات واختبار صحة الفروض على البرنامج الإحصائي (Statistical Package For Social Science) (SPSS الاجتماعية، لتفريغ البيانات وجدولتها وإجراء التحليل الإحصائي المناسب لتحليل البيانات ولإختبار صحة فروض الدراسة، وتطلب ذللك تطبيق بعض أساليب الإحصاء الوصفي والإحصاء التحليلي كالاتي :

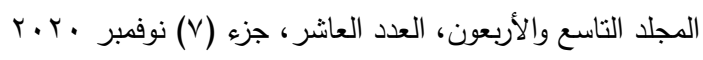

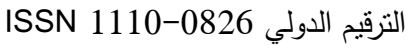


أ) الإحصاء الوصفي: تم الاعتماد على الإحصاء الوصفي وكل من الوسط الحسابي

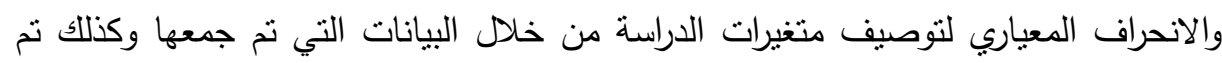

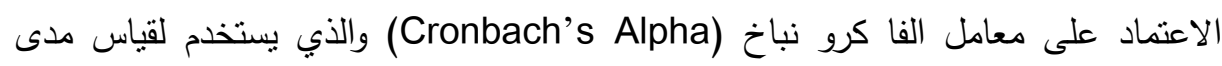
الصدق والثبات للأسئلة الموجودة في الاستقصاء، وكذلك التأكد من مدى أهمية هذه الأسئلة بالإضافة إلى استخدام معامل إرتباط بيرسون وذللك لقياس ثبات أداة الدراسة. ب) الإحصاء الاستدلالي: اعتمد الباحث على تحليل بيانات الدراسة على أساليب الإحصاء

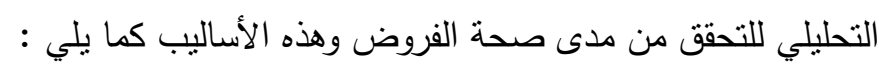
• تحليل الانحدار الخطي البسيط : هو اسلوب احصائي يستخدم لاختبار أثز متغير مستقل واحد على متغير تابع واحد بطريقة المربعات الصغرى OLS والذي يحتوي على اختبار

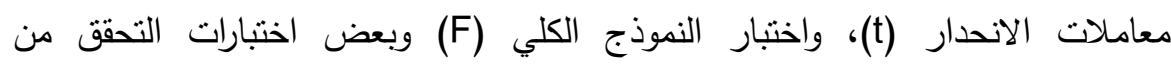

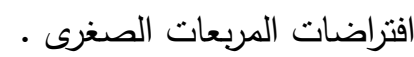
• تحليل الانحدار الخطي المتعدد : هو اسلوب احصائي يستخدم لاختبار أثر اكثر من متغير مستقل على متغير تابع واحد بطريقة المربعات الصغرى OLS والذي يحتوي على الانى

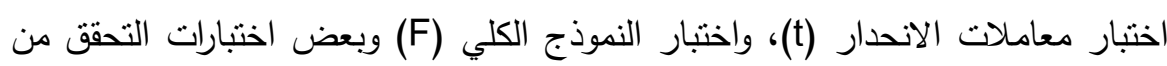

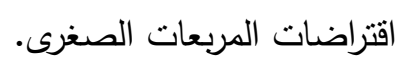

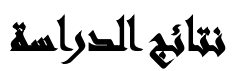

نعرض فيما يلي النتائج الخاصة بتطبيق الاستبيان علي عينة البحث وللتحقق من صحة

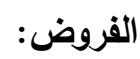

المحور الأول : نظام التكلفة علي اساس النشاط الموجه بالوقت: الجدول التالى يوضح الوسط الحسابى المرجح والانحراف المعيارى والأهمية النسبية

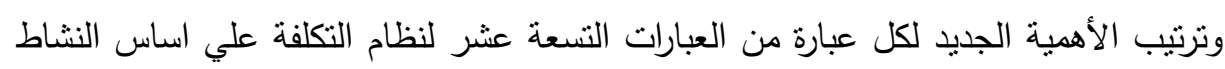

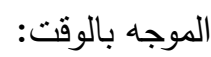

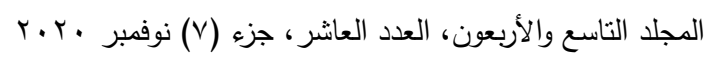

$$
\begin{aligned}
& \text { التزقيم الدولي 0826- ISSN 1110 نروني }
\end{aligned}
$$




$$
\begin{aligned}
& \text { مجلة العلوم البيئية } \\
& \text { معهد الدراسات والبحوث البيئية - جامعة عين شمس لئه } \\
& \text { بهاء محمد عبدالغني الغنام وآخرون }
\end{aligned}
$$

\begin{tabular}{|c|c|c|c|c|c|}
\hline ترتيبة & الإهمية & المعياري & الحسابي & الققــرة & 5 \\
\hline$\varepsilon$ & $0 \leqslant, Y q$ & $1,1 \cdot \varepsilon$ & $r, Y)$ & النشاط والنشاط الموجه بين التكاليف علي اساس & 1 \\
\hline 11 & $\varepsilon q, r \wedge$ & I, IYr & $r, \varepsilon V$ & تحرص النشاط الموكة علي تطبيق نظام التكلفة على & $r$ \\
\hline 19 & $\varepsilon r, r r$ & 1,119 & $r, I r$ & 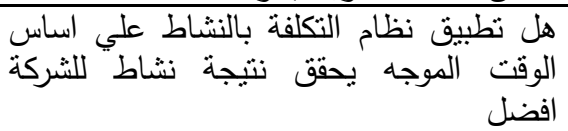 & $r$ \\
\hline 1 & $09, \leq 9$ & $1, E Y T$ & $r, q V$ & هل يوجد مسببات للتكلفة . & $\varepsilon$ \\
\hline 9 & חו, ט & ס מ, 1, & $r, 01$ & هناكت فرق بين مسببات التكلفة ومحركات & 0 \\
\hline iv & $\varepsilon \Gamma, T V$ & Trו & $r, \mid \wedge$ & 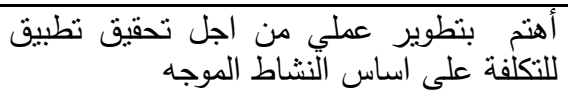 & 7 \\
\hline 7 & or,, 9 & $1, \cdot r r$ & $r, T$ & لدنقى الشركة القرة على حصر الأنشطة التى & $\mathrm{V}$ \\
\hline$\checkmark$ & or,, 9 & $1, r_{1}$ & $r, T$ & 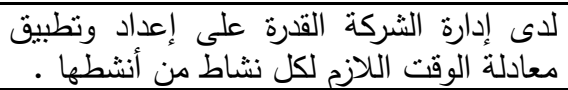 & $\Lambda$ \\
\hline it & $\varepsilon \wedge, \vee \uparrow$ & $1, I V Y$ & $Y, \varepsilon \varepsilon$ & الدباشرة الشركة القدرة على الفصل بين التكاليف & 9 \\
\hline 11 & $\varepsilon Y, T$ & $1,1 \cdot 9$ & $r, I T$ & الدى الثُركة القدرة على تحديد الأنشطة غير & 1. \\
\hline 17 & $\varepsilon 0, \vee 7$ & $1, \mathrm{r}_{1}$ & $r, r q$ & لاى الشركة القدرة على تحديد التكلفة الملائمة & 11 \\
\hline 1. & $\varepsilon q, \wedge r$ & $1, Y \backslash Y$ & $r, \varepsilon q$ & تقلى المنتجات بإعادة الخدمات. تخصيص نكاليف الأشطة & IT \\
\hline $1 \varepsilon$ & $\varepsilon \vee, \wedge$ & $1,1 T \varepsilon$ & $r, r q$ & 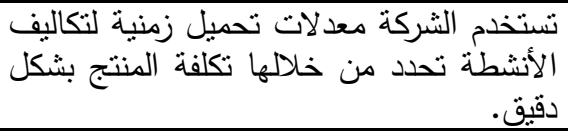 & $1 \pi$ \\
\hline 10 & $\varepsilon \vee, \varepsilon\rceil$ & $1,10 r$ & $r, r v$ & تلتكاليف الأنشطة الشركة تراعي معدلات العلاقة تحميل السبية متعددة بين & $1 \leq$ \\
\hline
\end{tabular}

جدول ( r ):الإحصائيات الوصفية لنظام التكلفة علي اساس النشاط الموجه بالوقت

$$
\text { المجلد التاسع والأربعون، العدد العاشر ، جزء (V) نوفمبر ·. r. }
$$


مجلة العلوم البيئية

معهد الدراسات والبحوث البيئية - جامعة عين شمس ليفه

بهاء محمد عبدالغني الغنام وآخرون

تابع: جدول ( r ):

\begin{tabular}{|c|c|c|c|c|c|}
\hline ترتيبة & الاهمية & الالمعياري & الحسبابي & الفقـــرة & r \\
\hline$r$ & $\infty 0, \wedge \wedge$ & $\cdot, 997$ & $r, \vee q$ & 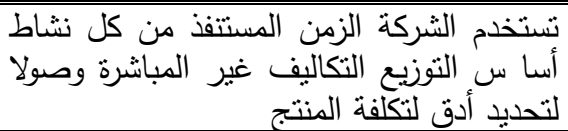 & 10 \\
\hline 0 & or,.o & $1,1 \cdot \varepsilon$ & $r, 70$ & 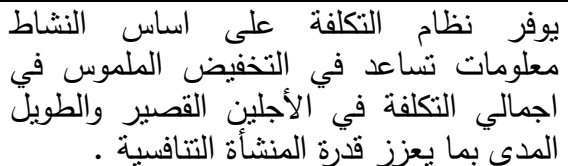 & 17 \\
\hline ir & $\varepsilon \Lambda, \cdot \Lambda$ & 1,100 & $Y, \Sigma$ & 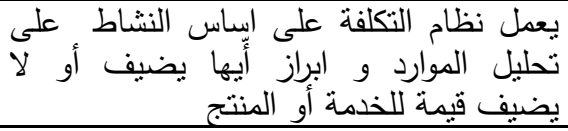 & 18 \\
\hline$\Lambda$ & $01, \leqslant 1$ & $1, Y \vee \varepsilon$ & $Y, O V$ & 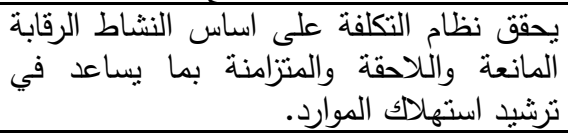 & 11 \\
\hline$r$ & $O \varepsilon, O r$ & $1,1 \pi v$ & $r, v r$ & 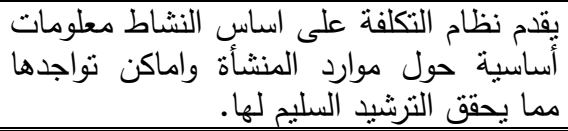 & 19 \\
\hline
\end{tabular}

يتضج من الجدول السابق أن :

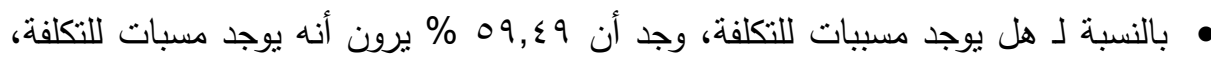

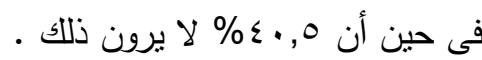

بالنسبة لتستخدم الثركة الزمن المستتف من كل نشاط أساس التوزيع التكاليف غير المباثرة

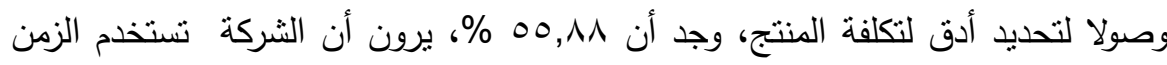

المستتف من كل نشاط أساس التوزيع التكاليف غير المباشرة وصولا لتحديد أدق لتكلفة

المنتج، فى حين ع ؛ \% لا برون ذلك.

بالنسبة ليقدم نظام التكلفة على اساس النشاط معلومات أساسية حول موارد المنشأة واماكن

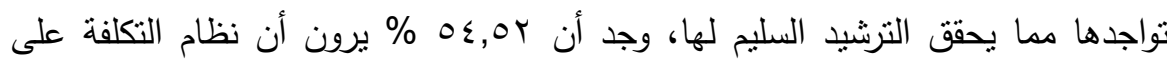

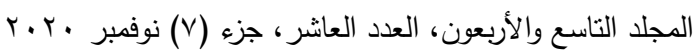

$$
\begin{aligned}
& \text { الترقيم الدولي 0826-1110 }
\end{aligned}
$$


اساس النشاط يقدم معلومات أساسية حول موارد المنشأة واماكن نواجدها مما بحقق الترشيد

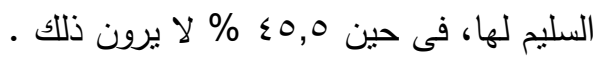

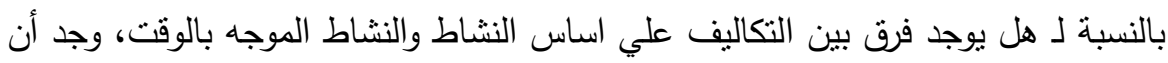

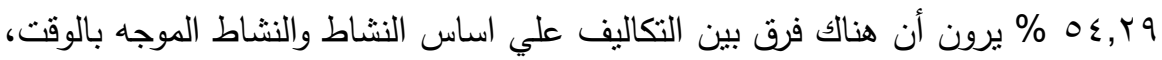

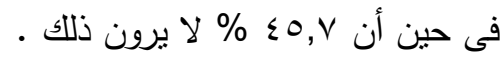
بالنسبة ليوفر نظام التكلفة على اساس النشاط معلومات تساعد في التخفيض الملموس في اجمالي التكلفة في الأجلين القصبر والطويل المدى بما يعزز قدرة المنشأة التتافسية،

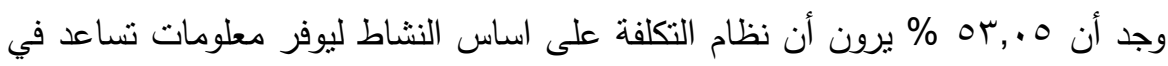
التخفيض الملموس في اجمالي التكلفة في الأجلين القصير والطويل المدى بما يعزز قدرة

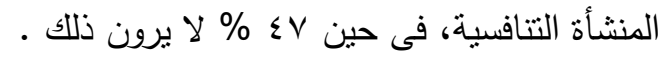

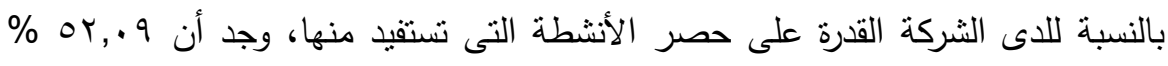

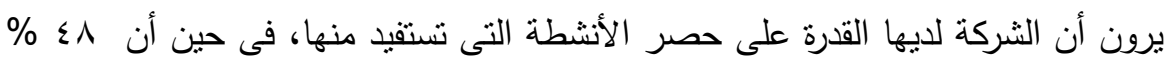
لا يرون ذللك مان. بالنسبة للاى إدارة الشركة القدرة على إعداد وتطبيق معادلة الوقت اللازم لكل نشاط من

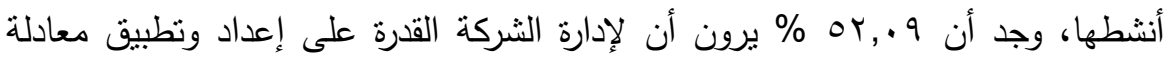

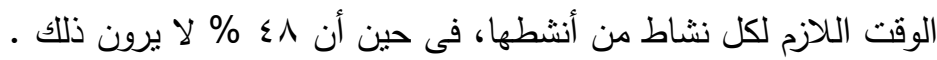

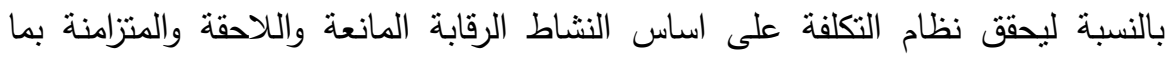

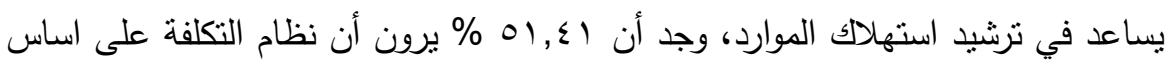
النشاط يحقق الرقابة المانعة واللاحقة والمتزامنة بما بساعد في ترشيد استهلاك الموارد .

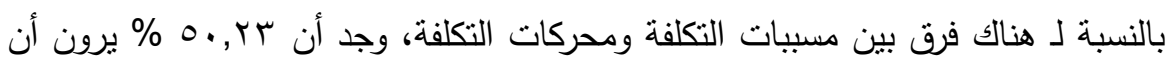
هناك فرق بين مسببات التكلفة ومحركات التكلفة .

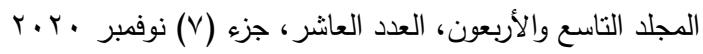

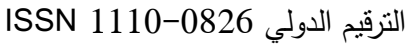


• بالنسبة لتقوم الثركة بإعادة تخصيص تكاليف الأنشطة على المنتجات و الخدمات، وجد

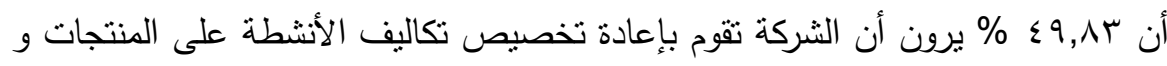
الخدمات .

• بالنسبة لتحرص الثركة علي تطبيق نظام التكلفة على اساس النشاط الموجه بالوقت، وجد

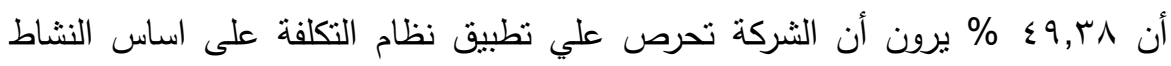

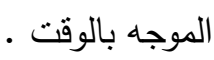

بالنسبة للدى الثركة القدرة على الفصل بين التكاليف المباشرة وغير المباشرة، وجد أن

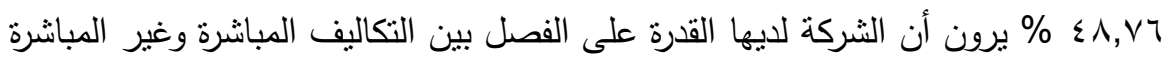

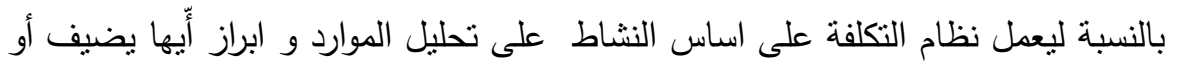

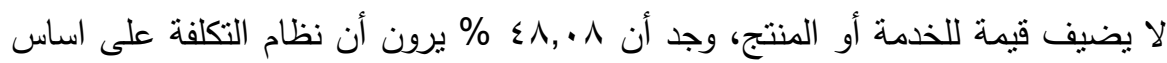
النشاط يعمل على تحليل الموارد و ابراز أبّها يضيف أو لا يضيف قيمة للخدمة أو المنتج بالنسبة لنستخدم الشركة معدلات تحميل زمنية لتكاليف الأنشطة تحدد من خلالها تكلفة

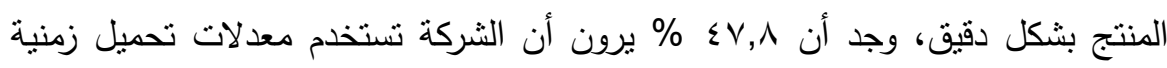

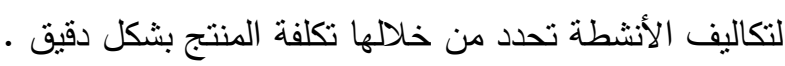
بالنسبة لنستخدم الشركة معدلات تحميل متعددة لتكاليف الأنشطة تراعى العلاقة السببية

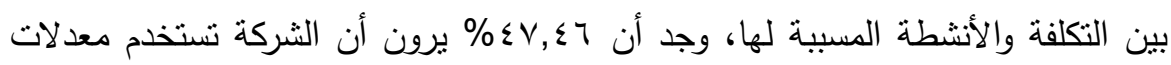

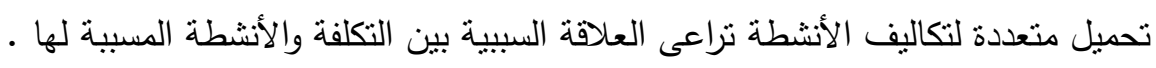

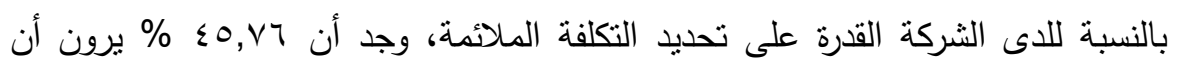

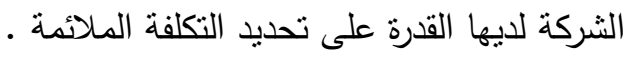

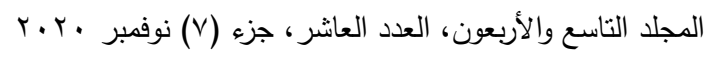

$$
\begin{aligned}
& \text { التزقيم الدولي }
\end{aligned}
$$




$$
\begin{aligned}
& \text { مجلة العلوم البيئية } \\
& \text { معهد الدراسات والبحوث البيئية - جامعة عين شمس للئن } \\
& \text { بهاء محمد عبدالغني الغنام وآخرون }
\end{aligned}
$$

• بالنسبة لأهتم بتطوير عملي من اجل تحقيق تطبيق للتكلفة على اساس النشاط الموجه،

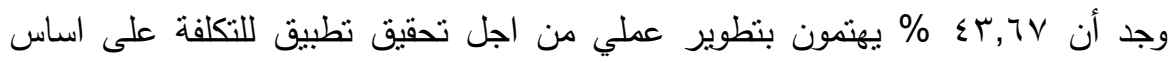

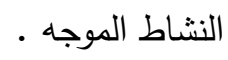

• بالنسبة للاى الثركة القدرة على تحديد الأنشطة غير المستغلة من الأنشطة، وجد أن

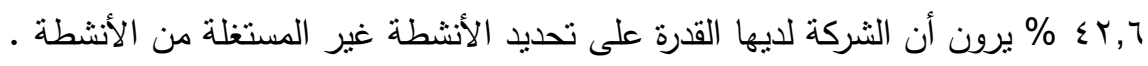

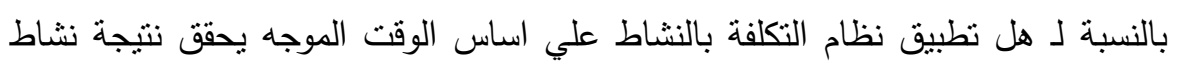

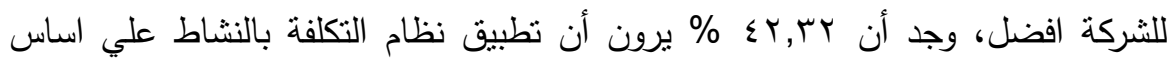
الوقت الموجه يحقق نتيجة نشاط للشركة افضل .

\section{المحور الثانى : معوقات تطبيق تكاليف الانشطة علي اساس النشاط :}

الجدول التإلى يوضح الوسط الحسابى المرجح والانحراف المعيارى والأهية النسبية وترتيب الأهية الجديد لكل عبارة من العبارات العشر لمعوقات تطبيق تكاليف الانشطة علي ولي ولهيك اساس النشاط.

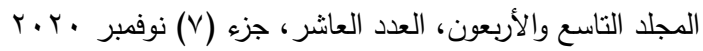

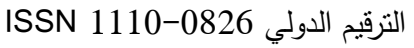


مجلة العلوم البيئية

معهذ الدراسات والبحوث البيئية - جامعة عين شمس لئه

بهاء محمد عبدالغني الغنام وآخرون

جدول ( r ): الإحصائيات الوصفية لمعوقات تطبيق تكاليف الانشطة علي اساس النشاط

\begin{tabular}{|c|c|c|c|c|c|}
\hline ترتيبة & الالهمية & الانحراف & المساببي & الققـــرة & p \\
\hline r & $\leqslant \vee, \ldots$ & $1, .99$ & 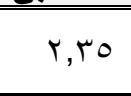 & لال يوجد تطبيق للنكلفة على اساس النشاط & 1 \\
\hline 7 & $\leq 7, \ldots$ & $1, r q r$ & $r, r$ & بمؤشترات مديري التكلفة على اساسات النشاطية والتكاليف & r \\
\hline$\varepsilon$ & $\Sigma \neg, \vee Y$ & $1, Y \wedge \vee$ & $r, r \varepsilon$ & 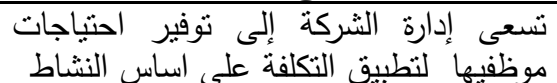 & $r$ \\
\hline r & L & 1, ror & r,0 & 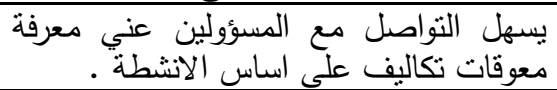 & $\varepsilon$ \\
\hline$\circ$ & $\leqslant 7,0$ & $1,1 \wedge \varepsilon$ & $r, r$ & ألاحظ أن معظم الإجراءات الإدارية معقدة. & 0 \\
\hline 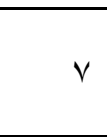 & $\varepsilon 0,9 \pi$ & 1,119 & $r, r$ & 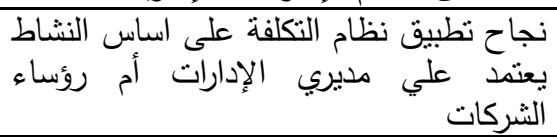 & 7 \\
\hline $1 \cdot$ & $\varepsilon \varepsilon, Y \leq$ & $1,1 \leq \wedge$ & $r, Y_{1}$ & 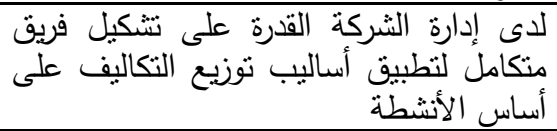 & $\mathrm{V}$ \\
\hline 9 & $\varepsilon \varepsilon, r q$ & $1,1 \cdot r$ & $r, Y_{1}$ & 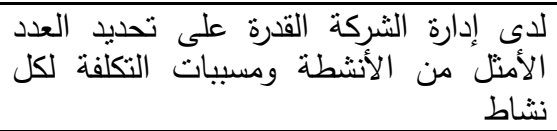 & $\Lambda$ \\
\hline 1 & or, 99 & 1,199 & r, 70 & لإداريا إدارة الثركة القدرة التى ألى من الأساليب القناع الحوظفينة & 9 \\
\hline$\wedge$ & $\varepsilon \varepsilon, 79$ & $1,1 \pi 1$ & r, r & 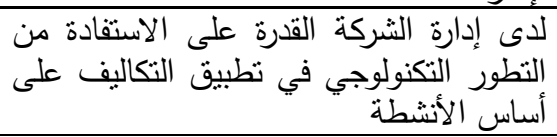 & 1. \\
\hline
\end{tabular}

بالنسبة للاى إدارة الثركة القدرة على إقناع الموظفين بمزايا التحول إلى أي من الأساليب

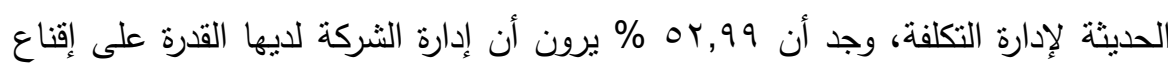
الموظفين بمزايا التحول إلى أي من الأساليب الحديثة لإدارة التكلفة.

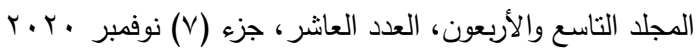

$$
\begin{aligned}
& \text { الترقيم الدولي 0826-1110 }
\end{aligned}
$$


بالنسبة ليسهل النواصل مع المسؤولين عني معرفة معوقات تكاليف على اساس الانشطة،

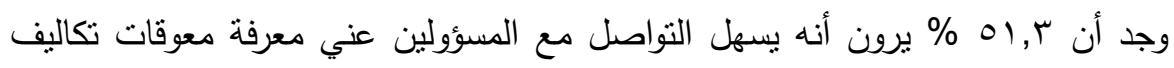

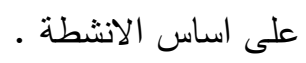

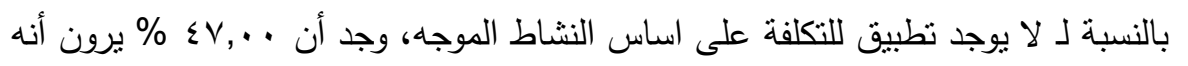

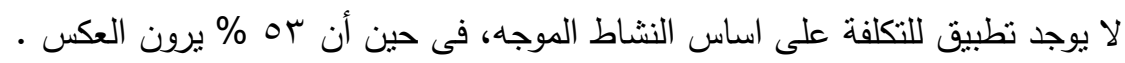

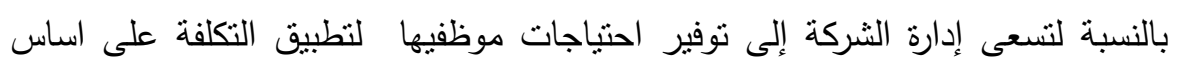

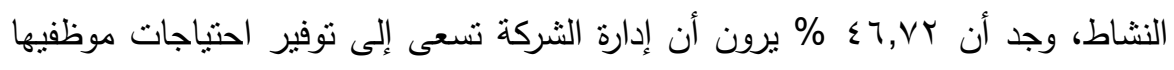

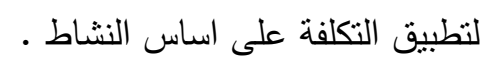

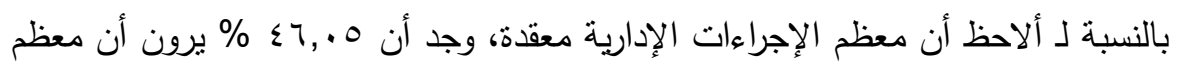

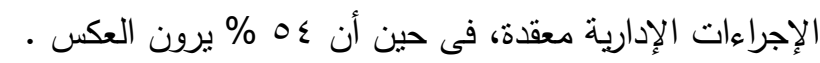

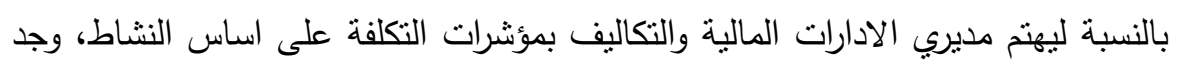

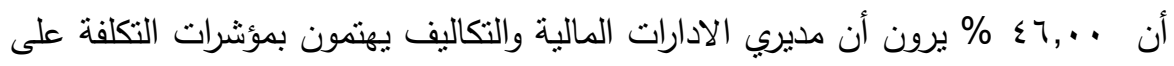
اساس النشاط . أن ان. بالنسبة لنجاح تطبيق نظام التكلفة على اساس النشاط يعتمد علي مديري الإدارات أم

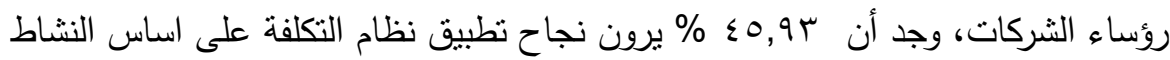
يعتمد علي مديري الإدارات أم رؤساء الشركات وات أنداء بالنسبة للاى إدارة الثركة القدرة على الاستفادة من التطور التكنولوجي في تطبيق التكاليف

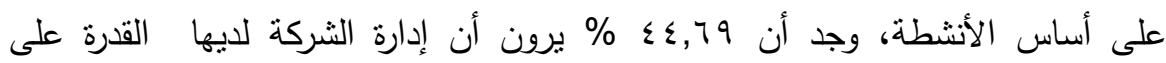
الاستفادة من التطور التكنولوجي في تطبيق التكاليف على أساس الأنشطة.

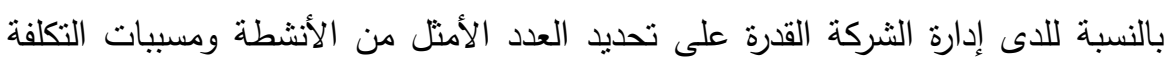

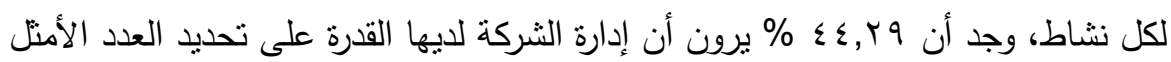

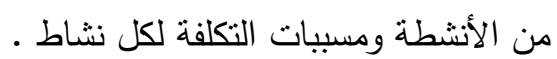

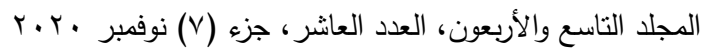

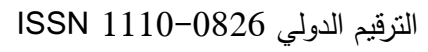


مجلة العلوم البيئية

معهد الدراسات والبحوث البيئية - جامعة عين شمس لبه

بهاء محمد عبدالغني الغنام وآخرون

• بالنسبة للاى إدارة الثركة القدرة على نتكيل فريق متكامل لتطبيق أساليب توزيع التكاليف

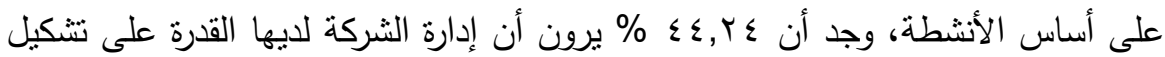
فريق متكامل لتطبيق أساليب توزيع التكاليف على أساس الأنشطة.

المحور الثالث : إتخاذ القرارات: الجدول التإلى يوضح الوسط الحسابى المرجح والانحراف المعيارى والأهمية النسبية وترتيب الأهمية الجديد لكل عبارة من العبارات الثمانية

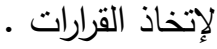

جدول ( ؛ ): الإحصائيات الوصفية لإتخاذ القرارات

\begin{tabular}{|c|c|c|c|c|c|}
\hline ترتيبة & النسبية الاهمية & الانحراف & المتوسط الحسبي & القق_ــرة & م \\
\hline 0 & $0 \wedge, r$ & $\cdot, 9 \vee \vee$ & $r, 91$ & ملائدمة نظام التخاذ القلة على السارات التشغيلية . لنشاط معلومات & 1 \\
\hline V & 00 & & $r, V_{0}$ & تقفيدم في اعداد التكلفة على اساس التخات النشاط معلومات & $r$ \\
\hline r & 71 & $1,1 \wedge \vee$ & $r, .0$ & 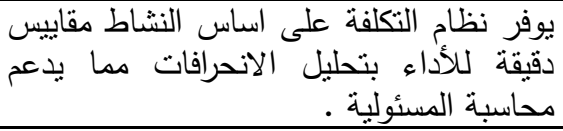 & $r$ \\
\hline 1 & $\neg \varepsilon, \wedge$ & rq & $r, r \varepsilon$ & 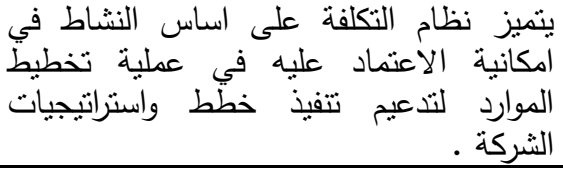 & $\varepsilon$ \\
\hline$\varepsilon$ & $0 \wedge, \varepsilon$ & $1, r \leqslant 9$ & $r, q r$ & الاحلال أو التكلفة الاستبدالية التاس لاتخاذ النشاط تكلفة & 0 \\
\hline 7 & 00,7 & 1,170 & $\curlyvee, \vee \wedge$ & 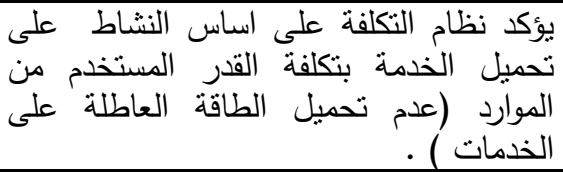 & 7 \\
\hline$r$ & $0 \wedge, 0$ & $1, r 19$ & $r, q r$ & 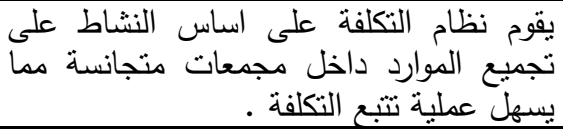 & $\mathrm{V}$ \\
\hline$\wedge$ & $0 \leqslant, Y$ & $1,1 \vee V$ & $Y, V I$ & 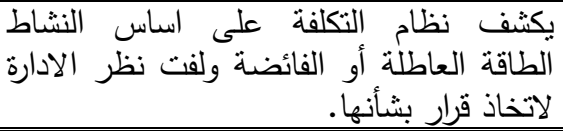 & $\Lambda$ \\
\hline
\end{tabular}




$$
\begin{aligned}
& \text { مجلة العلوم البيئية } \\
& \text { معهد الدراسات والبحوث البيئية - جامعة عين شمس للئن } \\
& \text { بهاء محمد عبدالغني الغنام وآخرون }
\end{aligned}
$$

$$
\text { يتضح من الجدول السابق أن: }
$$

• بالنسبة لـ يتميز نظام التكلفة على اساس النشاط في امكانية الاعتماد عليه في عملية

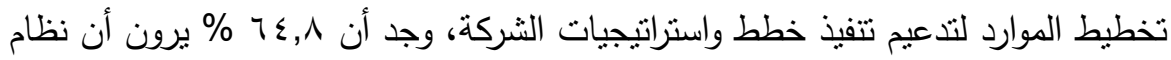
التكلفة على اساس النشاط يتميز في امكانية الاعتماد عليه في عملية تخطيط الموارد

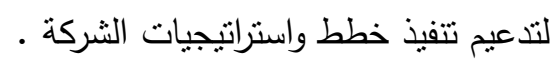

بالنسبة لـ يوفر نظام التكلفة على اساس النشاط مقاييس دقيقة للأداء بتحليل الانحرافات

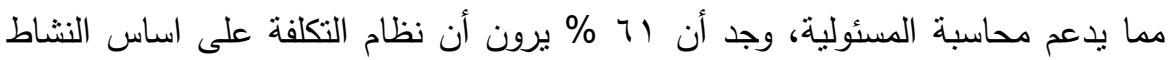
يوفر مقاييس دقيقة للأداء بتحليل الانحرافات مما يدعم محاسبة المسئولية . بالنسبة لـ يقوم نظام التكلفة على اساس النشاط على تجميع الموارد داخل مجمعات

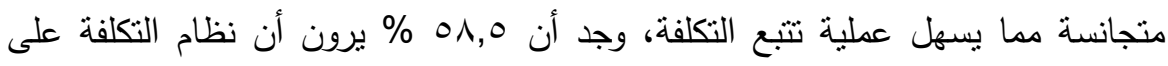

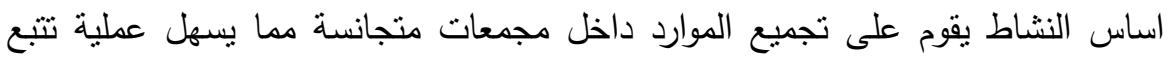
التكلفة .

بالنسبة لـ يستخدم نظام التكلفة على اساس النشاط تكلفة الاحلال أو التكلفة الاستبدالية

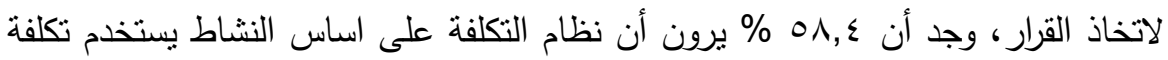

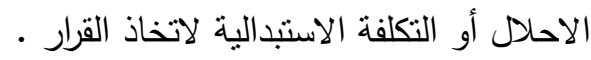
بالنسبة لـ يقدم نظام التكلفة على اساس النشاط معلومات ملائمة لاتخاذ القرارات التشغيلية،

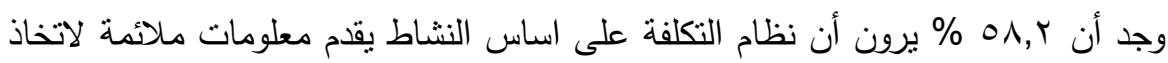

$$
\text { القرارات التشغيلية . }
$$

بالنسبة لـ يؤكد نظام التكلفة على اساس النشاط على تحميل الخدمة بتكلفة القدر

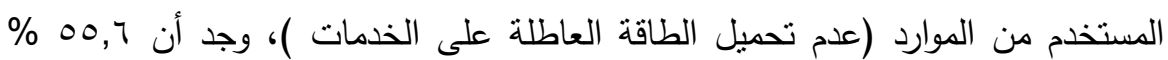
يرون أن نظام التكلفة على اساس النشاط يؤكد على تحميل الخدمة بتكلفة القدر المستخدم

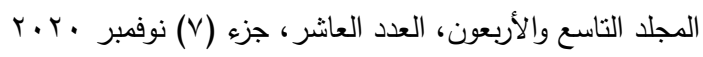

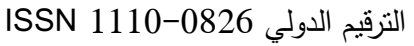


مجلة العلوم البيئية

معهد الدراسات والبحوث البيئية - جامعة عين شمس لبه

بهاء محمد عبدالغني الغنام وآخرون

بالنسبة لـ يقام نظام التكلفة على اساس النشاط معلومات تقيد في اعداد الموازنات

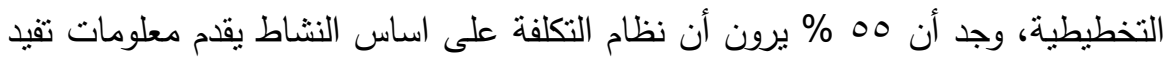

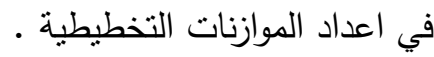
بالنسبة لـ يكثف نظام التكلفة على اساس النشاط الطاقة العاطلة أو الفائضة ولفت نظر

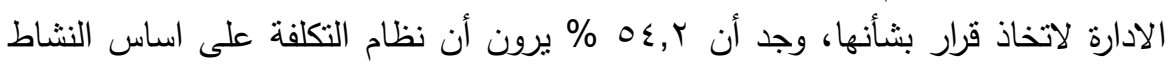

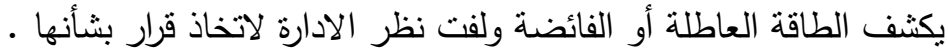

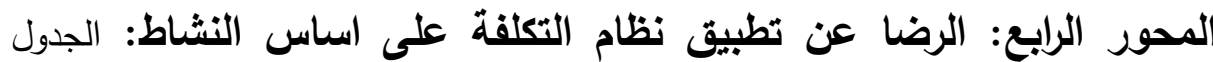
التإلى يوضح الوسط الحسابى المرجح والانحراف المعيارى والأهمية النسبية وترتيب الرئي الأهمية الجديد لكل عبارة من العبارات العشرون لالرضا عن تطبيق نظام التكلفة على اساس النشاط:

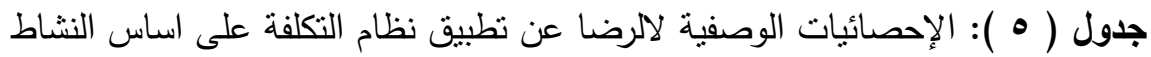

\begin{tabular}{|c|c|c|c|c|c|}
\hline الاهنيبة & الاهمبية & الانحراف & المتوسط & الفقــرة & م \\
\hline$\varepsilon$ & $0 \cdot, \wedge 0$ & 1,111 & $r, 0 \leqslant$ & أسلوب الرقابة الذي يتبعه رئيسك لمتابعة & 1 \\
\hline 1 & $01, \lambda 1$ & $1, \cdot T V$ & r,09 & أسلوب ضبط التكاليف مناسب بالشركة . & r \\
\hline Ir & $\varepsilon \vee, \Gamma \varepsilon$ & $1, \cdot 7 V$ & $r, r V$ & عملك الحالي مقارنة بخبرتك الوظيفية. & r \\
\hline$\Lambda$ & $\varepsilon \Lambda, \mu_{T}$ & $1,+Y \varepsilon$ & $Y, \leqslant Y$ & العدالة في توزيع أعباء العمل بين الموظفين. & $\varepsilon$ \\
\hline 9 & $\sum \Lambda, \cdot \Lambda$ & $1, \cdot 47$ & $r, \xi$ & الوحدة التي تقوم بالعمل فيها ؟ & 0 \\
\hline$r$ & $0 ., 9$ & $1, .19$ & $r, 00$ & الفرص التدريبية المتاحة للك في مجال عملك. & 7 \\
\hline 0 & $\varepsilon \wedge, \vee$ & $1, .01$ & $Y, \varepsilon \varepsilon$ & الثناء الذي نتلقاه من رئيسك لمتابعة أدائك. & $\bar{v}$ \\
\hline 11 & $\varepsilon \vee, \curlyvee \wedge$ & $1, .07$ & $r$, rی & تطبيق نظام التكلفة في فئك العمل تساعدك علي & $\wedge$ \\
\hline 10 & $\leqslant 0, \wedge r$ & $1,1 \wedge r$ & $r, r q$ & مستبر معوق للتكاليف للك عند زيادة حجم العمل & 9 \\
\hline 7 & $\varepsilon \wedge,\rceil \varepsilon$ & $1,10 \mathrm{~V}$ & $r, \varepsilon r$ & نقدير زملائك للك عند زيادة حجم العمل.يساهم في النشاط النيق & 1 . \\
\hline T & $\varepsilon 7, Y \vee$ & $1, \cdot \mathrm{r}$ & $r, r$ & النطوحبرية المسؤول عني باقتراحاتي وأفكاري & 11 \\
\hline$r$ & 01,19 & 1,101 & Y,07 & أشعر أن عملى سبب تطور قدراتي الثخصية & ir \\
\hline $\mathrm{V}$ & $\sum \wedge, 09$ & $1,1 Y V$ & $r, \varepsilon r$ & أعتبر عملي أقل الوظائف اجتماعيا. & 14 \\
\hline 1 . & $\sum \vee, \wedge$ & $1, \cdot 17$ & $r, r q$ & أشتعر ان عملى لا يناسب مؤهلاتي العلمية & $1 \varepsilon$ \\
\hline $1 \leq$ & $\{7,17$ & $1,1 \leq 1$ & $r, r$ & هل أنت رضي عن العمل بشكل عام & 10 \\
\hline
\end{tabular}




$$
\begin{aligned}
& \text { مجلة العلوم البيئية } \\
& \text { معهد الدراسات والبحوث البيئية - جامعة عين شمس لئن } \\
& \text { بهاء محمد عبدالغني الغنام وآخرون }
\end{aligned}
$$

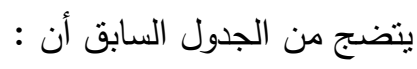

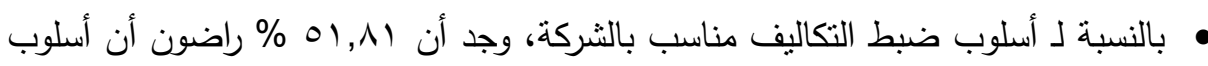

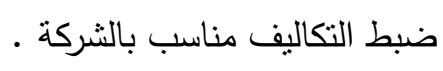

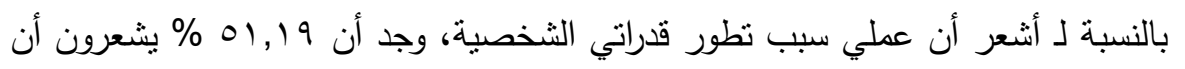

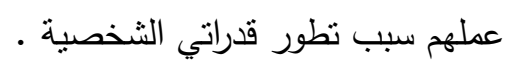

بالنسبة لـ الفرص التدريبية المتاحة للك في مجال عملك، وجد أن 9, هـ راضون أن

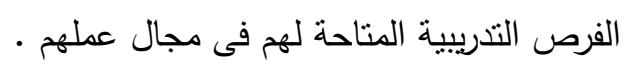

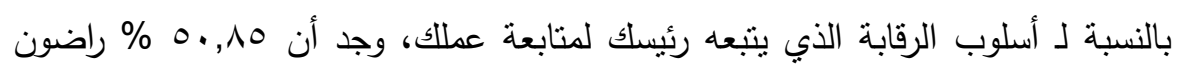

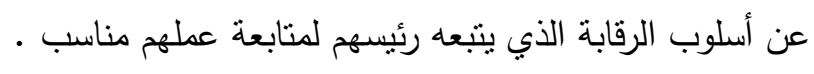

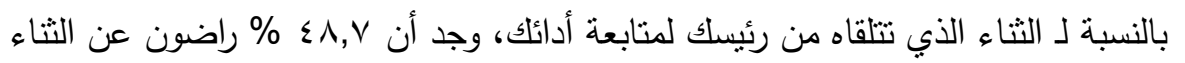

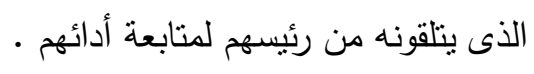

بالنسبة لـ تقدير زملاثك للك عند زيادة حجم العمل بساهم في نجاح تطبيق نظام التكاليف

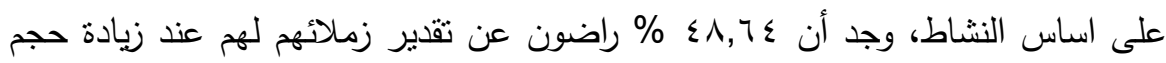

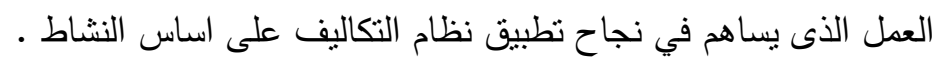

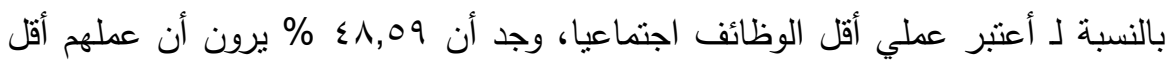

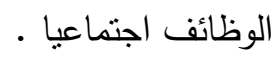

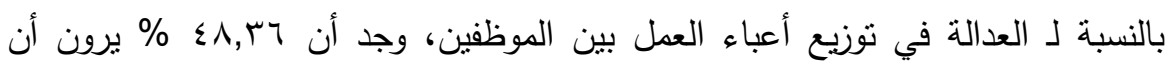

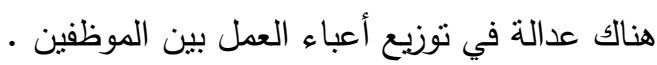

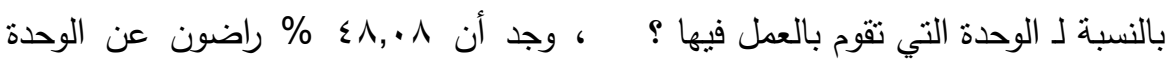

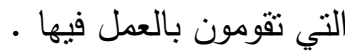

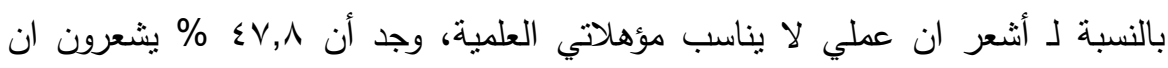

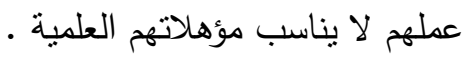

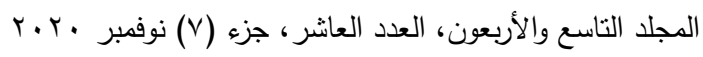

$$
\begin{aligned}
& \text { ISSN 1110-0826 التزقيم الدوني }
\end{aligned}
$$




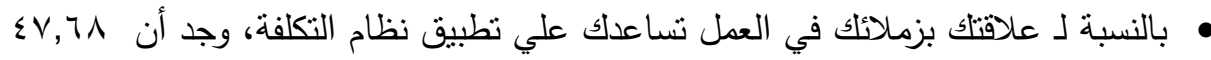
\% برون أن علاقتهم بزملائهم في العمل نساعدك علي نطبيق نظام التكلفة.

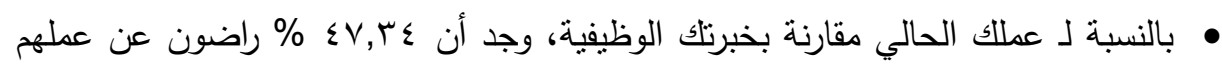

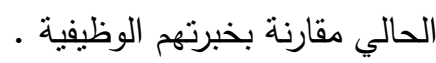

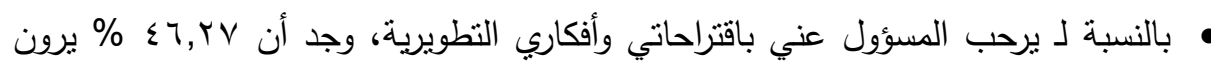

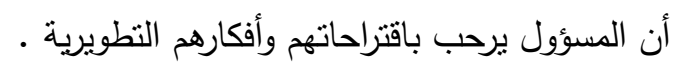

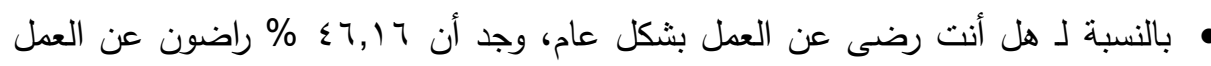

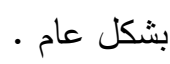
بالنسبة لـ مساعدة زملائك للك عند زيادة حجم العمل يعتبر معوق للتكاليف، وجد أن

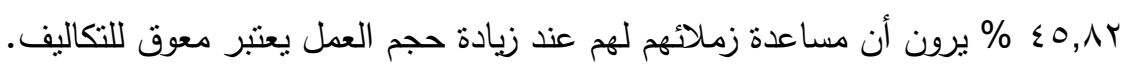

\section{توكيجامي القراسلا}

• تبني نظام TDABC قنبل المنشآت الصناعية، نظراً لسهولة نطبيقه ودقة قياسه لوحدة المنتج، وملاءمته لطبيعة البنية الصناعية المنتشرة بين معظم المنشآت الصناعية. • الاعتماد بشكل رئيسي على معطيات نظام محاسبة التكاليف في عملية بناء القرارات الإدارية، إذ يجب أن تتسم هذه المعطيات بالدقة والوقنية. • ربط عملية اتخاذ القرار بحجم ونسبة استغلال الطاقة الإنتاجية لموارد المنشأة المتاحة.

\section{هراع التواسم}

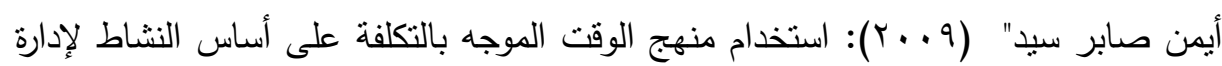

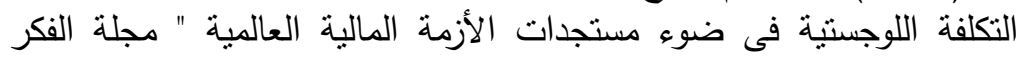
المحاسبي، كلية التجارة جامعة عين شمس العدد الأول الجزء الثاني.

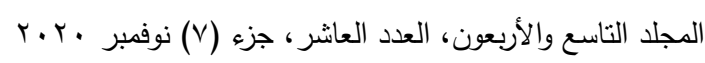

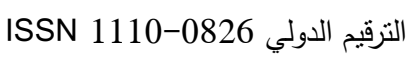




$$
\begin{aligned}
& \text { مجلة العلوم البيئية } \\
& \text { معهد الدراسات والبحوث البيئية - جامعة عين شمس لبه } \\
& \text { بهاء محمد عبدالغني الغنام وآخرون }
\end{aligned}
$$

عصافت سيد أحمد عاثشور (99V (1)): "معايير التكلفة في بيئة التصنيع الحديثة، إطار مقترح

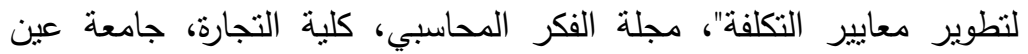

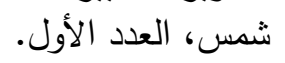

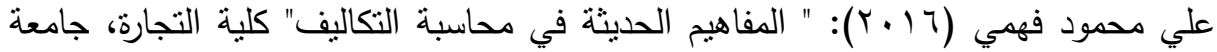

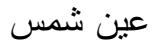

كمال حسين أحمد (7 ( ب): " الأساليب الحديثة في محاسبة التكاليف " كلية التجارة، جامعة

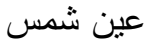

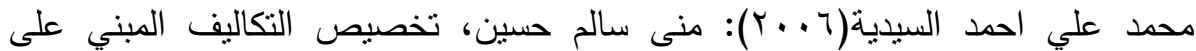

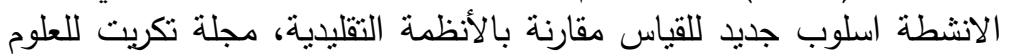

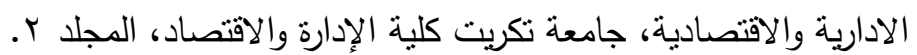

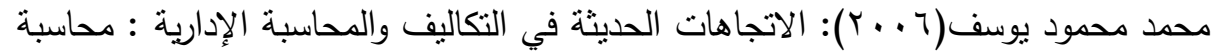

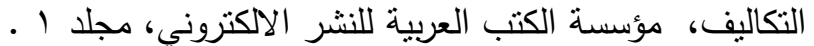

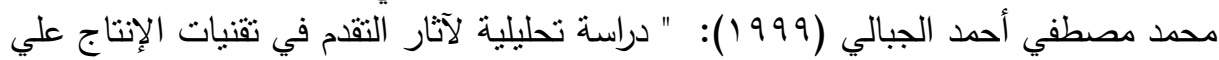

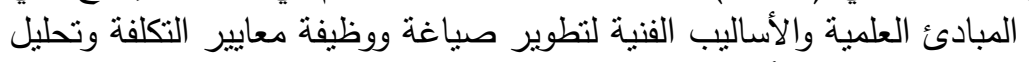
الانحرافات لخدمة أغراض رقابية وتخفيض التكلفة، دراسة ميدانية"، مجلة كلية التجارةن جامعة القاهرة فرع بني سويف العدابة العد الأول.

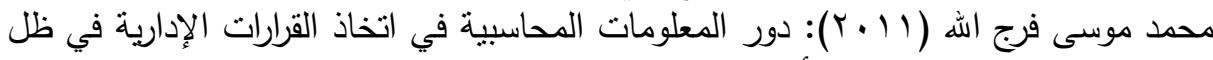

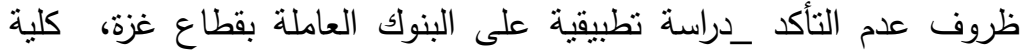

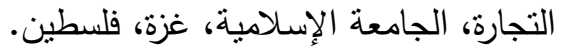

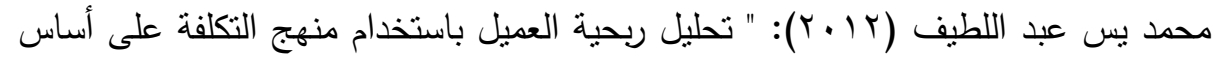

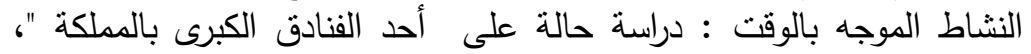

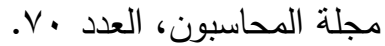

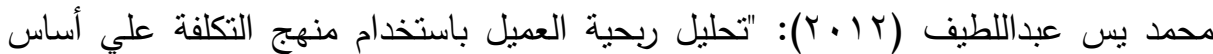

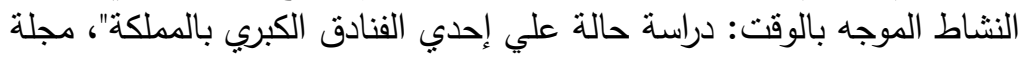
المحاسبون.

Board Of Studies (2013): " Decision Making Using Concepts And CVP Analysis " in "Advanced Management Accounting ", Final Course Study Material, Paper 5, ICAI, Vol.1, New Delhi, India.

Bruggeman W. (2010): " Full Economic Costing using Time-Driven Activity Based Costing", B\&M Consulting.

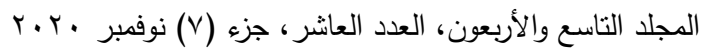

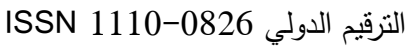




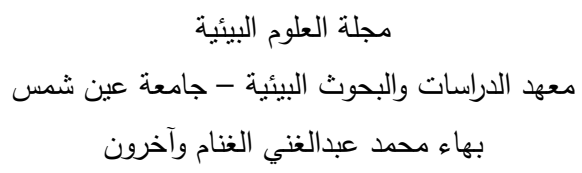

Chung T. T. (2011): " The Impact Of Accounting Information On Management's Decision Making - Vinamilk Case Study", Bachelor Thesis, Faculty of Business, Economics and Accounting, Help University, Malaysia.

Craig A. Latshaw et Teresa M. Cortese-Danile (2010): Activity-Based costing: usage and pitfalls, Trade Journal, Article, p: 5 .

Everaert P., et al. (2008): ,"Cost modeling in logistics using time-driven ABC: Experiences from a wholesaler", International Journal of Physical Distribution \& Logistics Management, Vol. 38,Iss: 3.

Fabienne Guerra (2007): Strategic management of the company, Deboeux , Brussels.

Garrison, R, H, .Noreen, E, W, and Brewer, P, C, Managerial Accounting,

Gervais M., Levant Y.\& Ducrocq C. (2010): "Time-Driven ActivityBased Costing (TDABC): An Initial Appraisal through a Longitudinal Case Study", JAMAR Journal, Vol.8,No 2.

Kaplan R.S.\& Anderson S.R. (2007):"The Speed-Reading Organization", business finance, June.

Tse M. S. C. \& Gong M. Z. (2009): "Recognition of Idle Resources in Time-Driven Activity-Based Costing and Resource Consumption Accounting Models", JAMAR Journal, Vol. 7, No 2.

$$
\begin{aligned}
& \text { المجلد التاسع والأربعون، العدد العاشر ، جزء (V) نوفمبر •r.r. } \\
& \text { الترقيم الدولي 0826-1110 }
\end{aligned}
$$




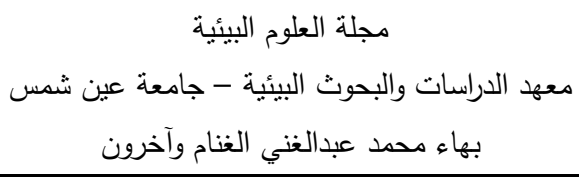

THE USE OF THE TIME-DRIVEN ACTIVITY

BASED COSTING SYSTEM IN PRODUCTIVE

PROJECTS IN ORDER TO ACHIVE

\title{
SUSTAINABLE DEVELOPMENT
}

\author{
Bahaa, M. A. El-Ganam ${ }^{(1)}$; Mohamed A. Khalifa ${ }^{(2)}$ \\ and Wael F. Abdel-Baset ${ }^{(2)}$
}

1) Post Grad., Student, Institute of Environmental Studies and Research, Ain Shams University 2) Faculty of Commerce, Ain Shams University

\begin{abstract}
The study aimed to propose a costing system on the basis of timedirected activity with defining the objectives and characteristics that must be met in the development process. Therefore, the researchers designed a survey list of workers in some companies operating in the activity-based costing system and a time-oriented costing system. The survey contained four axes for each the focus of a number of questions. The researchers used the descriptive and analytical method. The study sample was identified, which amounted to 168 individuals.

The researchers found that: There is a positive relationship between the application of the cost system on the basis of time-directed activity and the obstacles to the application of activity costs on the basis of activity.

The researchers recommended the necessity of adopting the TDABC system by industrial establishments, due to its ease of application, accuracy of measuring the unit of product, and its suitability for the nature of the industrial structure spread among most industrial establishments.
\end{abstract}

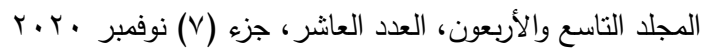

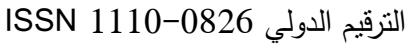

